Boise State University

ScholarWorks

$10-1-2012$

\title{
Phylogeny of a Neotropical Clade in the Gesneriaceae: More Tales of Convergent Evolution
}

John L. Clark

University of Alabama

Minde M. Funke

Boise State University

Aaron M. Duffy

Boise State University

James F. Smith

Boise State University 
Int. J. Plant Sci. 173(8):894-916. 2012.

(c) 2012 by The University of Chicago. All rights reserved.

1058-5893/2012/17308-0005\$15.00 DOI: $10.1086 / 667229$

\title{
PHYLOGENY OF A NEOTROPICAL CLADE IN THE GESNERIACEAE: MORE TALES OF CONVERGENT EVOLUTION
}

\author{
John L. Clark, ${ }^{1, *}$ Mindie M. Funke, $†$ Aaron M. Duffy, ${ }^{2,} \dagger$ and James F. Smith† \\ *Department of Biological Sciences, University of Alabama, Box 870345, Tuscaloosa, Alabama 35487, U.S.A.; and \\ tDepartment of Biological Sciences, Boise State University, 1910 University Drive, Boise, Idaho 83725, U.S.A.
}

\begin{abstract}
The Gesneriaceae is a family known for convergent evolution of complex floral forms. As a result, defining genera and resolving evolutionary relationships among such genera using morphological data alone has been challenging and often does not accurately reflect monophyletic lineages. The tribe Episcieae is the most diverse within Neotropical Gesneriaceae in terms of its number of species and morphological diversity. As a result, defining genera using floral characters has been historically troublesome. Here we investigate relationships among genera of the tribe using an array of chloroplast DNA, nuclear ribosomal genes, and low-copy nuclear genes to provide resolution for the monophyly of the genera and relationships among the monophyletic groups. All known genera in the tribe (with the exception of the monospecific Lampadaria) have been sampled, and most have been sampled to provide an assessment to determine their monophyly. Of the 17 genera in the tribe that comprise more than a single species, we have sampled 15 with at least two species. The following six genera are identified as para- or polyphyletic: Neomortonia, Episcia, Paradrymonia, Nantilocalyx, Codonanthe, and Nematanthus. Our results strongly support at least three independent origins of fleshy fruits, which are defined here as fleshy display capsules or indehiscent berries.
\end{abstract}

Keywords: Columnea, Drymonia, display capsules, Episcia, Episcieae, Gesneriaceae, Neomortonia, splash-cup seed dispersal, stolons.

Online enhancements: appendix table and figure.

\section{Introduction}

The exploration and discovery of morphological variation in a phylogenetic context is a mainstay of plant systematics and is one of the most revealing aspects of generating a specieslevel phylogeny that allows us to differentiate homology from convergence. An increased understanding of evolution and homology, coupled with an explosion in the number of studies that have relied on molecular data to resolve phylogenetic history (Palmer and Zamir 1982; Chase et al. 1993; Soltis et al. 1998; Leebens-Mack et al. 2005; Burleigh et al. 2011), has resulted in a greater appreciation of the convergence of character states across relatively large evolutionary distances (Chase et al. 1993; APG III 2009; Endress 2011) as well as among closely related species where morphological similarities were presumed to be homologous (Mummenhoff et al. 1997; Clark and Zimmer 2003; Jousselin et al. 2003; Vences et al. 2003; Smith et al. 2004b; Roalson et al. 2005a, 2005b).

Phylogenetic analyses of Gesneriaceae over the past 20plus years have helped resolve the homology of many morphological characters and revealed the convergence of many

\footnotetext{
${ }^{1}$ Author for correspondence; e-mail: jlc@ua.edu.

2 Current address: Department of Biology, Utah State University, 5305 Old Main Hill, Logan, Utah 84322, U.S.A.
}

Manuscript received December 2011; revised manuscript received May 2012. more. Broader-level sampling has provided support for the division of the family into two clades, the primarily Paleotropical Cyrtandroideae and almost exclusively Neotropical Gesnerioideae (Smith et al. 1997; Mayer et al. 2003; Möller et al. 2009), and for the monophyly of many of the tribes within the Gesnerioideae (Smith 1996, 2000a, 2000b, 2000c; Smith and Carroll 1997; Smith et al. 1997; Smith and Atkinson 1998; Zimmer et al. 2002; Woo et al. 2011). In contrast, there has been little support for many of the tribes of the Cyrtandroideae except Epithematae (Smith et al. 1997; Mayer et al. 2003; Möller et al. 2009), and in the Gesnerioideae the tribe Sphaerorrhizeae was discovered with molecular data, which was not foreseen from morphological data alone (Roalson et al. 2005a).

At finer scales in Gesneriaceae, the problems of defining monophyletic groups are exacerbated by the convergence of corolla morphologies. The monophyly of numerous genera in the Gesnerioideae has been questioned, including Neomortonia and Paradrymonia (Smith 2000b); Alloplectus, Nautilocalyx, and Paradrymonia (Clark and Zimmer 2003; Clark et al. 2006); and Phinaea, Capanea, Kobleria, and Gloxinia (Smith et al. 2004a; Roalson et al. 2005a, 2005b, 2008; Clark et al. 2011). Similar problems at the generic level exist in the Cyrtandroideae (Möller and Cronk 1997; Smith et al. 1998; Möller et al. 2009; Wang et al. 2010, 2011).

The utility of molecular phylogenetic analyses to recover monophyletic clades whose constituent species can then be surveyed for character states to support the clade has become 
the new mainstay in plant systematics (Tekle et al. 2009). Within Gesneriaceae, this method has been useful within the tribe Gloxinieae, where several monospecific genera have been found to belong to a single clade and combined (Gloxinia erinoides [DC] E. H. Roalson \& J. K. Boggan, G. xanthophylla [Poeppig] E. H. Roalson \& J. K. Boggan), and other genera (Monopyle and Phinaea) have been found to be polyphyletic (Smith et al. 2004b; Roalson et al. 2005b; Clark et al. 2011). Once monophyletic groups have been identified, it is possible to reexamine the morphology of the species that fall into the separate clades and determine traits that define the taxa and redefine generic boundaries. A striking example is Phinaea s.l. These plants form small rosettes and produce scapose inflorescences with several flowers with nearly actinomorphic white corollas. Actinomorphy is relatively rare among Neotropical Gesneriaceae, and therefore the tendency to include these species in a single genus was not surprising. However, phylogenetic analyses placed these species in two unrelated clades (Smith et al. 2004a; Roalson et al. 2005b, 2008). When examined more closely, it turned out that one clade had nodding flowers (Amalophyllon) and the other had erect flowers (Phinaea; Boggan et al. 2008). Recently, another species, Phinaea pulchella, has been found to be phylogenetically unrelated to either of the two previously recognized clades and may merit an additional generic name (Clark et al. 2011).

Another major clade of Neotropical Gesneriaceae where similar problems are being discovered with increased taxon sampling is the tribe Episcieae. Like Gloxinieae, the tribe Episcieae is morphologically diverse (fig. 1) but has long been considered monophyletic on the basis of its three-trace trilacunar nodal anatomy, axillary flowers derived from reduced pair-flowered cymes, and a base chromosome count of $x=8$ or 9 (Wiehler 1983; Weber 2004). The combination of these traits is not known among other Neotropical Gesneriaceae. Molecular-based phylogenetic analyses have supported the monophyly of this tribe (Smith and Carroll 1997; Smith et al. 1997; Smith 2000b; Zimmer et al. 2002; Smith et al. 2004a, 2004b; Roalson et al. 2005a, 2005b; Clark et al. 2006), although support and number of species sampled has varied. Despite this, the monophyly of several genera in the tribe have been suspect on the basis of these analyses, including Neomortonia (Smith and Carroll 1997; Smith 2000b), Paradrymonia (Clark et al. 2006; Smith 2000b), and most notably Alloplectus, which was recovered in no less than six clades across the tribe (Clark and Zimmer 2003; Clark et al. 2006).

Clark et al. (2006) sampled Episcieae most recently and more thoroughly in terms of species than previous studies. Despite this, several clades were not strongly supported or fully resolved on the basis of molecular data alone, and the inclusion of morphology was necessary to boost support and resolution for many clades, including the monophyly of $\mathrm{NeO}-$ mortonia, which contradicted previous studies based on molecular data alone (albeit poorly supported; Smith and Carroll 1997; Smith 2000b). The goal of this study is to revisit the phylogenetic analyses of Episcieae and to sample more broadly among chloroplast DNA (cpDNA; Shaw et al. 2007) and low-copy nuclear DNA (Emshwiller and Doyle 1997; Perret et al. 2003; Smith et al. 2004a, 2004b; Woo et al. 2011) regions, which have been shown to increase support among taxa that have been particularly recalcitrant at revealing evolutionary relationships. In particular, we were interested in resolving the monophyly and sister relationships among the genera associated with Glossoloma and Colum$n e a$, as these genera have been the research focus for two of the authors in previous studies (Smith and Sytsma 1994a, 1994b, 1994c; Smith 1994; Clark and Zimmer 2003; Clark 2009).

\section{Material and Methods}

A complete list of samples, voucher specimens, and GenBank accession numbers can be found in appendix A. DNA was extracted using either CTAB (Doyle and Doyle 1987) or DNeasy Plant Mini kits (Qiagen, Valencia, CA). In some instances, different individuals of the same species were used for different gene regions. These are not considered problematic since they were from species that we are confident are monophyletic.

Our analyses were at two levels. For the full analysis, we sampled comprehensively among species from all genera of tribe Episcieae except Lampadaria. For these species, we sampled the following cpDNA regions: $\operatorname{trnL}-\operatorname{trn} F$ and the trnL intron (using primers $\mathrm{c}$ and $\mathrm{d}$ and primers $\mathrm{e}$ and $\mathrm{f}$ of Taberlet et al. 1991), the rps16 intron (using primers from Oxelman et al. 1997), the rpl20-rps12 spacer (Hamilton 1999), the nuclear ribosomal internal transcribed spacer region (ITS1, 5.8S, and ITS2; hereafter referred to as ITS), the low-copy nuclear loci GCYC (using the primers of Citerne et al. [2000] and Smith et al. [2004a]), and nuclear-encoded chloroplast-expressed glutamine synthetase loci $(n c p G S$ herein, using primers 687f and 956r of Emshwiller and Doyle 1997). Two loci of different size are typically recovered from Gesneriaceae with the $n c p G S$ primers used here (Smith et al. 2004a) and are referred to herein as $n c p G S 1$ and $n c p G S 2$.

For the reduced analysis, we focused on the clade recovered from the full analysis, which included Alloplectus, Columnea, Corytoplectus, Crantzia, Drymonia, and Neomortonia. We removed some species in genera that had been recovered as monophyletic in the full analysis to focus our effort on increasing the number of DNA regions sampled per individual, thus improving support for relationships among genera. Therefore, in addition to the eight regions sampled for the full analysis, an additional six DNA regions were sampled, including five cpDNA regions $\left(r p l 32-t r n L_{U A G}\right.$ and $t r n Q-r p s 16$ spacers, both from Shaw et al. [2007], and $\operatorname{trnS}-\operatorname{trn} G$ and $\operatorname{trnD}-T$ spacers, from Demesure et al. [1995]), along with the nuclear DNA phosphoenolpyruvate carboxylase ( $P e p C$, from Malcomber [2002]).

Most cpDNA regions, GCYC, and $n c p G S$ were amplified and sequenced according to Smith et al. (2004b). The ITS regions and $t r n H-p s b A$ regions were amplified following Clark et al. (2006). Sequences were obtained either through the methods described in Smith et al. (2004a) or by sending samples to Genewiz (South Plainfield, NJ). Chromatograms were viewed and sequences edited and aligned by hand in PhyDe (http://www.phyde.de/). Most regions had missing data at the beginning and end in the full alignment. Additionally, the 

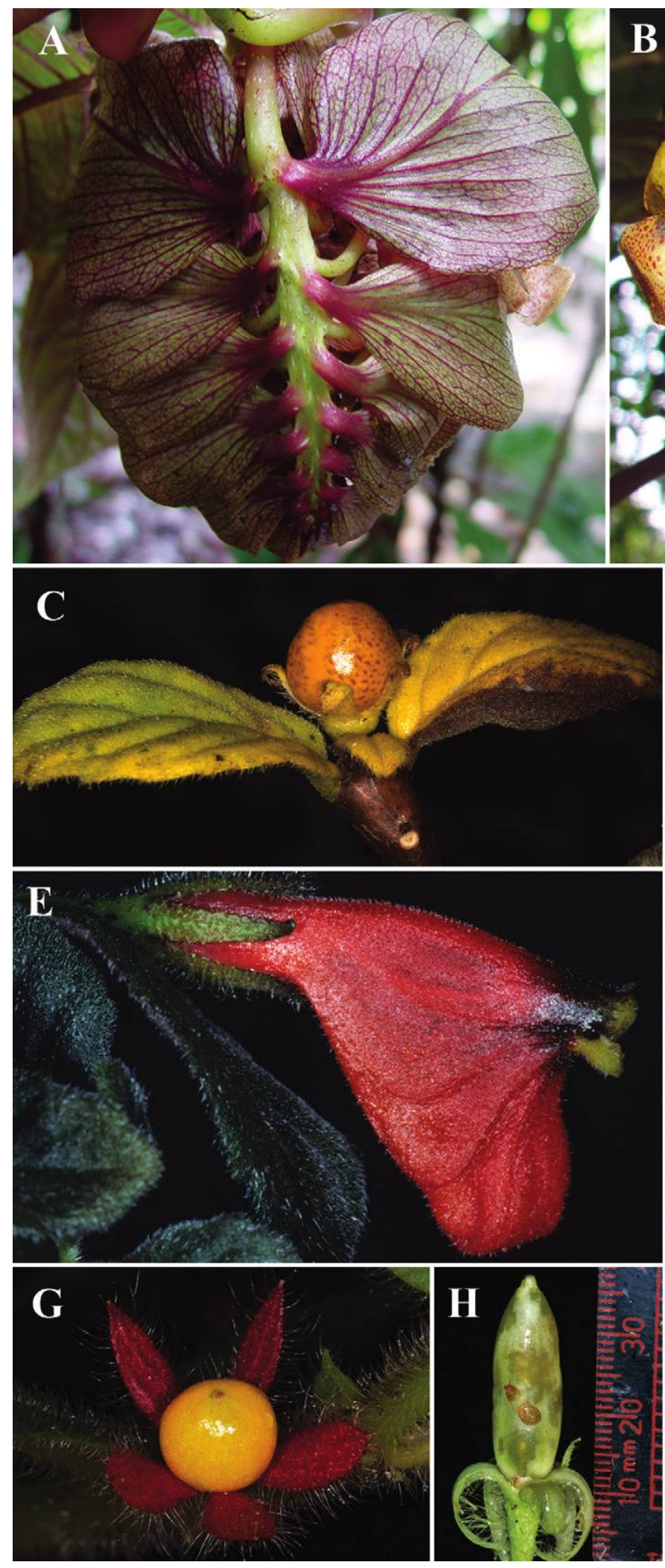

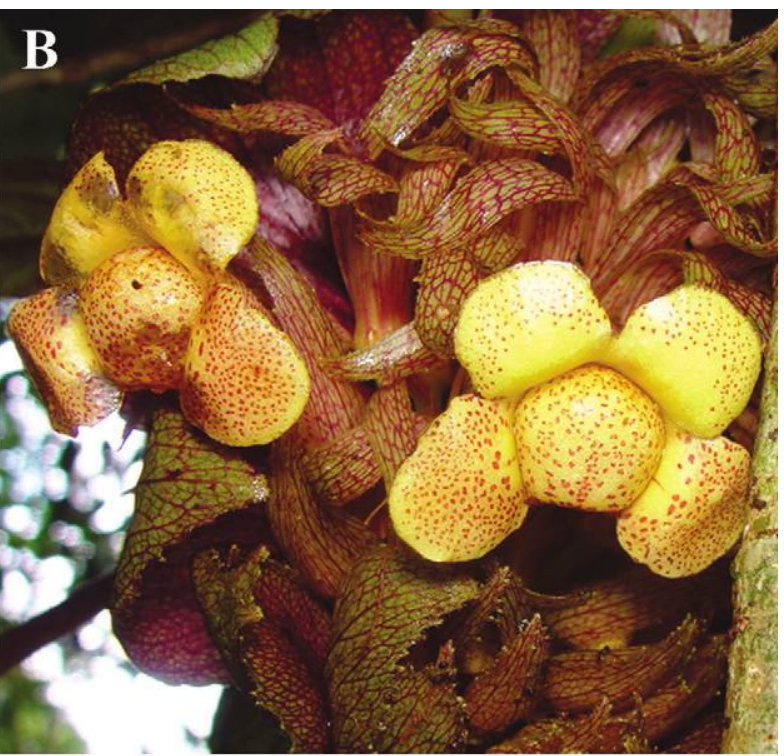

\section{D}

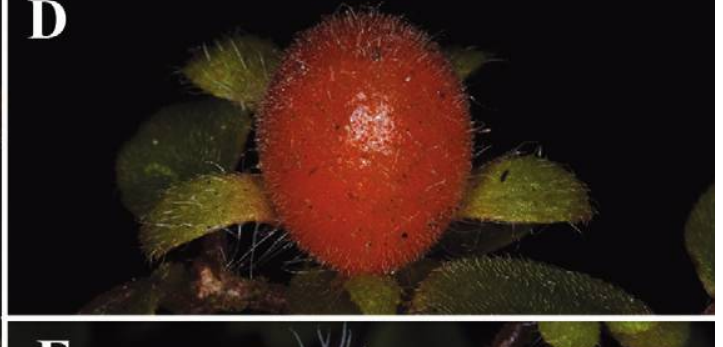

$\mathbf{F}$

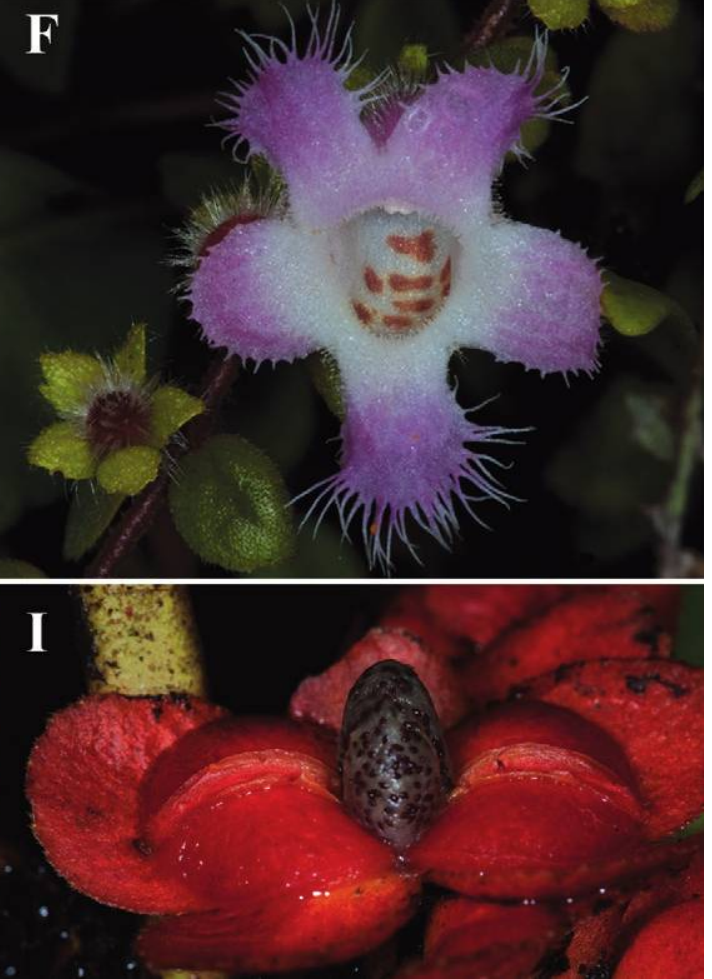

Fig. 1 Variation in flowers and fruits in Episcieae. A, Bracteate pendent inflorescence of Paradrymonia maculata. B, Occluded corolla via inflexed ventral lobe in P. maculata. C, Orange globose berry of Neomortonia nummularia. D, Orange, laterally compressed berry of Neomortonia rosea. E, Hypocyrtoid corolla of N. nummularia. F, Campanulate corolla with fringed lobes of N. rosea. G, Globose berry of Columnea tenella. H, Elongate berry of Columnea sp. nov. I, Fleshy bivalved capsule of Drymonia coriacea. (Voucher specimens at US: A, B, J. F. Smith et al. 4134; C, J. L. Clark 12360; D, J. L. Clark 11190; E, U.S. Botany Research Greenhouse accession number 1994-522; F, J. L. Clark 11041; G, J. L. Clark 10435; H, J. L. Clark 7649; I, J. L. Clark 11039. Photos: A, B by Chris Davidson, C-I by John L. Clark.) 
alignment produced regions of ambiguity due to single base pair or microsatellite repeats. Areas of missing data and ambiguous alignments were excluded from phylogenetic analyses. The alignments also resulted in gaps to account for indel events. While the inclusion of indels can often be of phylogenetic significance (Simmons and Ochoterena 2000), the indels generated here were primarily either autapomorphic or found only in the outgroup species. A total of 19 indels have potential phylogenetic significance in the full analysis (three in ITS, one in $G C Y C$, four in $n c p G S 1$, two in $n c p G S 2$, three in the trnL intron, two in the trnL-F spacer, three in the rps16 intron, and one in the rpl12-rps20 spacer). In the reduced analysis, 13 indels had potential phylogenetic utility (two in the rpl32-trnL spacer, two in the trnQ-rps16 spacer, one in the trnD-T spacer, four in the trnS-G spacer, and one in the $\operatorname{trn} H$ $p s b A$ spacer). Indels were treated as missing data and then rescored as presence or absence characters. This approach allowed for single-site and multiple-site gaps to be treated with equal weight (Simmons and Ochoterena 2000).

The outgroup samples were chosen on the basis of previous phylogenetic studies of Gesneriaceae and Episcieae, and we follow Woo et al. (2011) in recognizing eight tribes within subfamily Gesnerioideae: Beslerieae, Episcieae, Gesnerieae, Gloxinieae, Napeantheae, Sinningieae, Coronanthereae, and Sphaerorrhizeae. Because our analysis was focused on tribe Episcieae, we included outgroups from it and Gesnerieae, Gloxinieae, Sinningieae, and Sphaerorrizeae, since these five tribes have been demonstrated to form a well-supported monophyletic clade separate from the remaining tribes of Gesnerioideae (Woo et al. 2011). The reduced analysis was rooted using Crantzia, as indicated from results of the full analysis.

\section{Test of Incongruence}

The incongruence length difference (ILD) test (Farris et al. 1994) was performed as the partition homogeneity test implemented in PAUP $* 4.0 b 10$ (Swofford 2002) with 1000 bootstrap replicates (using a heuristic search, simple addition, and no branch swapping). The cpDNA, ITS, ncpGS1, $n c p G S 2, P e p C$, and GCYC were each treated as separate partitions for both full and reduced analyses. As the ILD test has been shown to indicate incongruence where none exists (Dolphin et al. 2000; Yoder et al. 2001; Barkworth and Lutzoni 2002; Dowton and Austin 2002), bootstrap analyses were performed on each partition separately to assess areas of conflict and to determine whether any conflict was strongly supported (Mason-Gamer and Kellogg 1996; Seelanen et al. 1997; Smith 2000c).

\section{Phylogenetic Analyses}

Phylogenetic trees were estimated using maximum parsimony (MP), maximum likelihood (ML), and Bayesian inference (BI). MP analyses were performed using PRAP2 (Müller 2004) in conjunction with PAUP $* 4.0$ b10 (Swofford 2002). Bootstrap support (BS) for nodes (Felsenstein 1985) was estimated with 1000 heuristic replicates using PRAP2. Descriptive statistics reflecting the amount of phylogenetic signal in the parsimony analysis were given by the consistency index
(CI; Kluge and Farris 1969), retention index (RI; Farris 1989), and the resulting rescaled consistency index (RC).

ML analyses were performed using optimal substitution models suggested by Modeltest 3.6 (Posada and Crandall 1998). The Akaike Information Criterion (AIC), which allows nonnested models to be evaluated, was used as a selection criterion (Posada and Buckley 2004). The GTR $+\Gamma$ model was chosen for the full analysis and GTR $+\Gamma+I$ for the reduced. Analyses of ML were completed using GARLI 0.96 (Zwickl 2006) with 100 bootstrap replicates.

BI analyses were completed using MrBayes 3.1.1 (Huelsenbeck and Ronquist 2003), using either a single model across the entire data set with the models used for ML or partitioned models with a different model for each of the partitions as determined by AIC in Modeltest 3.6 (full analysis: $\mathrm{ITS}=\mathrm{GTR}+\Gamma, G C Y C=\mathrm{HKY}+\Gamma, n c p G S 1=\mathrm{GTR}+\Gamma$, $n c p G S 2=\mathrm{K} 81 \mathrm{uf}+\Gamma, \mathrm{cpDNA}=\mathrm{TVM}+\Gamma$; reduced analysis: ITS $=$ GTR $+\Gamma, G C Y C=$ TVM $+\Gamma, n c p G S 1=$ $\mathrm{TVM}+\Gamma, n c p G S 2=\mathrm{KHY}+\Gamma, P e p C=\mathrm{HKY}+\Gamma, \mathrm{cpDNA}=$ GTR $+\Gamma)$. All analyses were run with four to one heated chains for 10 million generations. Convergence was determined by viewing in Tracer 1.3 (Rambaut and Drummond 2005), and a burn in of 50,000 generations was discarded prior to sampling the posterior distribution. The analyses were repeated twice to ensure that parameter estimates converged to similar values. The separate runs were compared using the online version of AWTY (http://king2.scs.fsu.edu /CEBProjects/awty/awty.php?fromStart=1\&sessionDir $=$ tmp18595; Nylander et al. 2008) as a means of determining whether the separate chains approximated the same target distribution. We report the $50 \%$ majority-rule consensus tree sampled from the posterior probability distribution.

The phylogenetic trees and data sets used in the full and reduced analyses have been submitted to TreeBASE (study 12668). SIMMAP 1.5 used Bayesian stochastic character mapping to perform the ancestral state reconstructions. The bias parameter was set to the empirical prior, and the rate parameter was set to the branch length prior with the character state changes unordered. Ancestral character state reconstructions using the branch length (BL) model in SIMMAP 1.5 are given as Bayesian posterior probabilities.

\section{Results}

Amplifications were successful for all regions for all individuals, with some exceptions for each DNA region (app. A). Table 1 presents a complete list of gene regions and combined data matrix statistics for the full analysis. Of the eight gene regions sampled in the full analysis, ITS provided the most parsimony-informative substitutions (317, or $47 \%$ ), whereas the trnL intron provided the least number of parsimony-informative substitutions $(86$, or $15 \%$; table 1$)$. The aligned matrix for the full analysis contained 4815 characters (4796 bp and 19 indels); of these, 2109 were constant and 1432 were uninformative. The complete matrix for the full analysis contained $1274(26.5 \%)$ phylogenetically informative characters.

The aligned matrix for the reduced analysis contained 8966 characters (8953 bp and 13 indels); of these, 7236 were constant and 1329 were parsimony uninformative. The ma- 
Table 1

Statistics for Chloroplast DNA and Nuclear Ribosomal DNA Genic Regions for the Full Analysis

\begin{tabular}{|c|c|c|c|c|c|c|c|c|}
\hline Statistic & ITS & GCYC & $n c p G S 1$ & $n c p G S 2$ & $\operatorname{trn} L$ intron & $\operatorname{trn} L-F$ spacer & rps16 intron & $\begin{array}{l}\text { rpl12-rps } 20 \\
\text { spacer }\end{array}$ \\
\hline Aligned length & 678 & 585 & 547 & 475 & 558 & 413 & 682 & 840 \\
\hline Mean GC content ( $\%)$ & $57.6(57.9)$ & $40.5(40.4)$ & $37.7(37.7)$ & $43.1(43.1)$ & $36.7(35.7)$ & $37.0(37.0)$ & $32.6(33.3)$ & $35.1(35.5)$ \\
\hline Mean pairwise divergence ( $\%)$ & $13.0(11.1)$ & $4.32(4.02)$ & $7.34(6.66)$ & $5.73(5.30)$ & $3.58(2.94)$ & $3.52(3.21)$ & $4.22(4.09)$ & $3.12(2.80)$ \\
\hline $\begin{array}{l}\text { Parsimony-uninformative } \\
\text { substitutions }\end{array}$ & $151(155)$ & $199(182)$ & $167(165)$ & $122(116)$ & $179(182)$ & $131(133)$ & $278(279)$ & $205(188)$ \\
\hline $\begin{array}{l}\text { Parsimony-informative } \\
\text { substitutions }\end{array}$ & $317(272)$ & $132(114)$ & $190(158)$ & $128(106)$ & $86(64)$ & $93(66)$ & 153 (119) & $156(120)$ \\
\hline Constant characters & $210(251)$ & $254(292)$ & $190(224)$ & $225(253)$ & $293(312)$ & $189(214)$ & $269(302)$ & $479(532)$ \\
\hline Consistency index & $.416(.456)$ & $.748(.757)$ & $.656(.692)$ & $.615(.642)$ & $.807(.853)$ & $.793(.841)$ & $.748(.772)$ & $.694(.713)$ \\
\hline Retention index & $.621(.648)$ & $.758(.759)$ & $.633(.640)$ & $.691(.719)$ & $.740(.747)$ & $.655(.699)$ & $.656(.661)$ & $.690(.700)$ \\
\hline Rescaled consistency index & $.258(.295)$ & $.567(.574)$ & $.415(.443)$ & $.428(.461)$ & $.568(.637)$ & $.519(.588)$ & $.491(.510)$ & $.479(.499)$ \\
\hline Tree length & $1860(1466)$ & $588(490)$ & $888(658)$ & $561(452)$ & $434(373)$ & 371 (308) & 794 (687) & $657(522)$ \\
\hline
\end{tabular}

Note. Values in parentheses are for the ingroup only (i.e., Episcieae).

trix contained $401(4.5 \%)$ phylogenetically informative characters (table 2 ).

The ILD indicated significant levels of incongruence for both the full and the reduced analysis $(P=0.01)$; however, separate BS analyses for each partition in the full analysis indicated conflicts, with BS $>75$ only for the monophyly of Episcia xantha in the GCYC data set (although both individuals were in the same clade) and the placement of Nematanthus savannarum with Nautilocalyx melittifolius and Paradrymonia metamorphophylla and Alsobia punctata as sister to Cobananthus with ncpGS1 (trees not shown). Both of these are low-copy nuclear genes and, despite previous work with both loci that did not detected additional paralogs for Gesnerioideae outside of Coronanthereae, it may be that there is additional allelic or paralog diversity for these regions in these two individuals. Therefore, the GCYC sequences for E. xantha 2 and ncpGS1 for N. savannarum and A. punctata were removed and replaced with missing data in the full analysis. Despite these conflicts, all other data sets indicated the same relationships for E. xantha, N. savannarum, and A. punctata; therefore, we used a combined data approach for the remainder of this study.

The MP analysis for the full sampling and indels treated as missing data resulted in 48 trees of length 6411 (CI $=0.59$, $\mathrm{RI}=0.62$, and $\mathrm{RC}=0.36)$. The strict consensus of these trees is shown in figures 2 and 3. The BS values were nearly identical for indels treated as missing or rescored. The ML analysis resulted in a tree $(-\ln$ likelihood $=42,751.72118)$ of nearly identical topology to the MP tree with indels scored as missing. The only difference is that the Episcia s.s. and Central American clades were in a polytomy with the Alloplectus/ Columnea/Drymonia clade, and the Southeastern Brazilian Atlantic Forest clade was sister to these clades (tree not shown; Nematanthus albus was sister to Nematanthus fritschii but with $\mathrm{BS}=64$ ). The two BI runs (both with a unique model for each data partition and a single model across all data) produced a majority-rule consensus tree mostly in agreement with the strict consensus of the MP analysis with indels scored as missing, and posterior probability (PP) values differed between the two runs by only a single point for nodes with $\mathrm{PP}<100$. The primary difference between the models was that a single model placed the Episcia s.s. clade sister to the Central American clade $(\mathrm{PP}=79)$ and these two clades as sister to the Alloplectus/Columnea/Drymonia clade $(\mathrm{PP}=96)$. Output from AWTY analyses showed that the independent runs of each data set were close in parameter (tree) space; thus, we could conclude that the two separate runs approximated the same target (tree) distribution.

The analyses recovered 10 clades consisting of more than a single genus with MPBS, MLBS, and PP > 95 within Episcieae. Six of these are labeled in figures 2 and 3. The remaining four strongly supported clades are either found within one of the labeled clades or consist of more than one of them. Relationships among the clades are mostly well supported with the exception of the clade sister to the remainder of the tribe and the relationship among the Episcia s.s., Central American, and Southeastern Brazilian Atlantic Forest clades. Seven genera (Chrysothemis, Columnea, Corytoplectus, Crantzia, Glossoloma, Rhoogeton, and Rufodorsia) for which more than a single species was sampled were strongly supported as monophyletic (MPBS, MLBS, PP > 95 for all except Glossoloma, with MPBS $=68$, MLBS = 100; fig. 3). Another eight genera (Alsobia, Codonanthe, Drymonia, Episcia, Nautilocalyx, Nematanthus, Neomortonia, and Paradrymonia) were not supported as monophyletic, and five genera (Alloplectus, Cobananthus, Codonanthopsis, Cremersia, and Lembocarpus) were represented by only a single species and thus were not tested here, although all are monospecific except for Alloplectus and Codonanthopsis.

The MP analysis for the reduced sampling with indels scored as missing resulted in two trees of length 2262 $(\mathrm{CI}=0.57, \mathrm{RI}=0.67, \mathrm{RC}=0.56)$. The two trees differed only in whether Glossoloma martinianum was sister to Glossoloma panamense or was sister to all remaining species in the genus. The strict consensus is shown in figure 4. Rescoring indels resulted in the same two trees (length $=2265$, $\mathrm{CI}=0.57, \mathrm{RI}=0.67, \mathrm{RC}=0.56$ ), and support was not altered. All genera except Neomortonia were recovered as monophyletic with strong support (fig. 4). Relationships among all genera were strongly supported in the reduced analysis, providing sister-group relationships among these genera for the first time using only molecular data. The ML analysis 


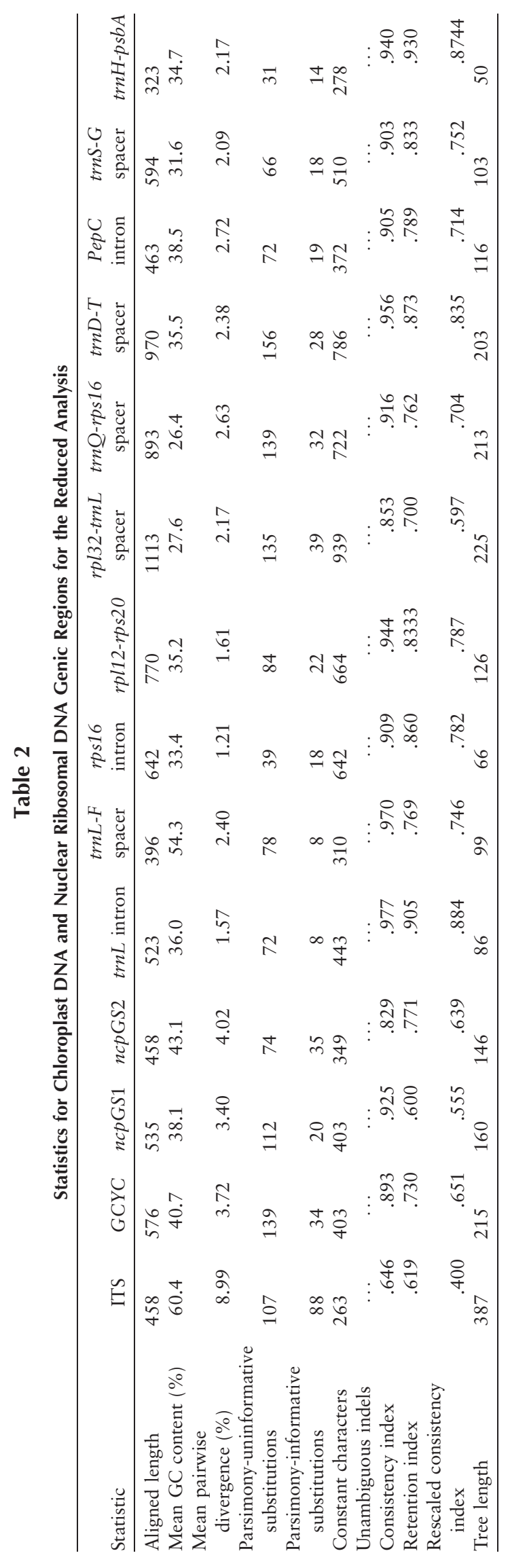


resulted in a single tree $(-\ln$ likelihood $=28,400.094456)$ that was completely congruent with the MP tree that placed $G$. martinianum as sister to all other species included in Glossoloma (fig. 4). The two BI runs (both with a unique model for each data partition and with a single model across all data) produced a majority-rule consensus tree in full agreement with the ML analysis, and PP values were identical between runs. Output from AWTY analyses showed that the independent runs of each data set were in close parameter (tree) space; thus, we can conclude that the two separate runs approximated the same target (tree) distribution.

The reduced analysis (fig. 4) is the first molecular-based phylogeny that provides strong support for intergeneric relationships in this clade. Our results strongly support that Glossoloma is sister to Columnea and places Neomortonia rosea as sister to Drymonia, with the latter clade sister to the Glossoloma/Columnea clade. Alloplectus is sister to these four taxa, with Neomortonia nummularia as sister to all other genera except Corytoplectus and Crantzia.

\section{Discussion}

The results of this analysis provide a well-supported phylogenetic estimate for most clades within tribe Episcieae based entirely on molecular data (Smith and Carroll 1997; Smith 2000b; Clark et al. 2006). Although Clark et al. (2006) sampled more broadly among the species of Episcieae, particularly among species-rich genera, their analyses were not able to resolve all relationships with molecular data alone, and support for some clades was not strong. In this analysis, we were able to take advantage of those data and sample fewer species in the clades that were recovered as monophyletic by sampling additional DNA regions, including several low-copy nuclear loci that provide an independent source of data for the evolutionary history of these taxa. Each of the well-supported clades is discussed in detail below.

\section{Paradrymonia, Nautilocalyx, and Chrysothemis}

The Paradrymonia + Nautilocalyx + Chrysothemis clade received strong support from all analyses (figs. 2, 5) and has been recovered (at least in part) in other analyses (Smith and Carroll 1997; Smith 2000b; Zimmer et al. 2002; Clark and Zimmer 2003; Clark et al. 2006). Paradrymonia is not monophyletic in this analysis, as species nest in other clades (e.g., Paradrymonia maculata shown in fig. 2) as well as the paraphyly of the majority of Paradrymonia, with the inclusion of a polyphyletic Nautilocalyx and a monophyletic Chrysothemis (figs. 2, 5). Smith and Carroll (1997) and Smith $(2000 b)$ also failed to recover a monophyletic Paradrymonia based on $n d h F$ and a combined ITS and $n d h F$ data set, respectively; however, this was mainly due to Paradrymonia densa falling outside the clade, as only three species of Paradrymonia and only one each of Nautilocalyx and Chrysothemis were sampled. The results recovered here are more similar to those of Clark et al. 2006, who also noted that Drymonia longifolia (=Paradrymonia longifolia in Clark et al. 2006) nested in Drymonia and that Paradrymonia ani- sophylla (not sampled here) was sister to Codonanthe + Codonanthopsis.

While it is clear that species of Paradrymonia falling outside this clade will need to be reassigned to other genera, it is not immediately obvious how to solve the problem of paraphyly among the bulk of the species in this clade. One option is to recognize a single large genus encompassing all species of Nautilocalyx and Chrysothemis. A second option is to divide Paradrymonia and Nautilocalyx into multiple genera. Greater species sampling will be essential to resolve this problematic clade, and it is the current focus of a $\mathrm{PhD}$ dissertation (M. Mora, in preparation).

This study strongly supports the sister group relationship of the clade comprising Paradrymonia + Nautilocalyx + Chrysothemis as the sister group to the remainder of Episcieae (all three analyses with $>95 \%$ support values). Smith and Carroll (1997) and Smith (2000b) also recovered this relationship, but with no support. The results presented here differ from those of Clark et al. (2006), where the sister clade to Episcieae was a strongly supported clade comprising Cremersia + Lembocarpus + Rhoogeton. Taxon sampling representing species from these two clades differ by inclusion of additional species from the Guyana Shield (e.g., Episcia xantha and $P$. maculata) in the current study. In contrast, taxon sampling in Clark et al. (2006) was limited to Rhoogeton vivaparus, Rhoogeton cyclophyllus, Cremersia platula, and Lembocarpus amoenus. Additional ongoing studies of Paradrymonia (M. Mora, personal communication) that have more extensive taxon sampling also suggest that the Paradrymonia, Nautilocalyx, and Chrysothemis complex is the sister clade to the rest of Episcieae.

\section{Guyana Shield Clade}

The Guyana Shield clade is strongly supported as monophyletic on the basis of support values from the three analyses and includes the monospecific genera Cremersia and Lembocarpus as well as the two species of Rhoogeton. Smith and Carroll (1997) did not sample any of these species, and Smith $(2000 b)$ included an ITS sequence for one species of Rhoogeton derived from herbarium material that was likely partly fungal in origin, as its placement on the tree varied depending on the analysis. Clark et al. (2006) recovered Cremersia, Lembocarpus, and a monophyletic Rhoogeton as sister to the remainder of Episcieae. The current study is the first to include P. maculata and E. xantha, and as a result neither species is found to be with the remainder of their genus, making Episcia polyphyletic for the first time.

Species in this clade have unique morphologies compared with other members of Episcieae, but there are no known morphological characters that unite them. For example, both Lembocarpus and Rhoogeton are tuberous with one to a few basal leaves and flowers borne on a scapose stem. In contrast, $P$. maculata is an herbaceous vine with a large bracteate pendent inflorescence (fig. $1 A$ ).

One aspect that all these species have in common is that they are endemic to the Guyana Shield, indicating that additional species from this region should be sampled to verify their placement. While the placement of most species in this clade has not been overly surprising given their unusual mor- 


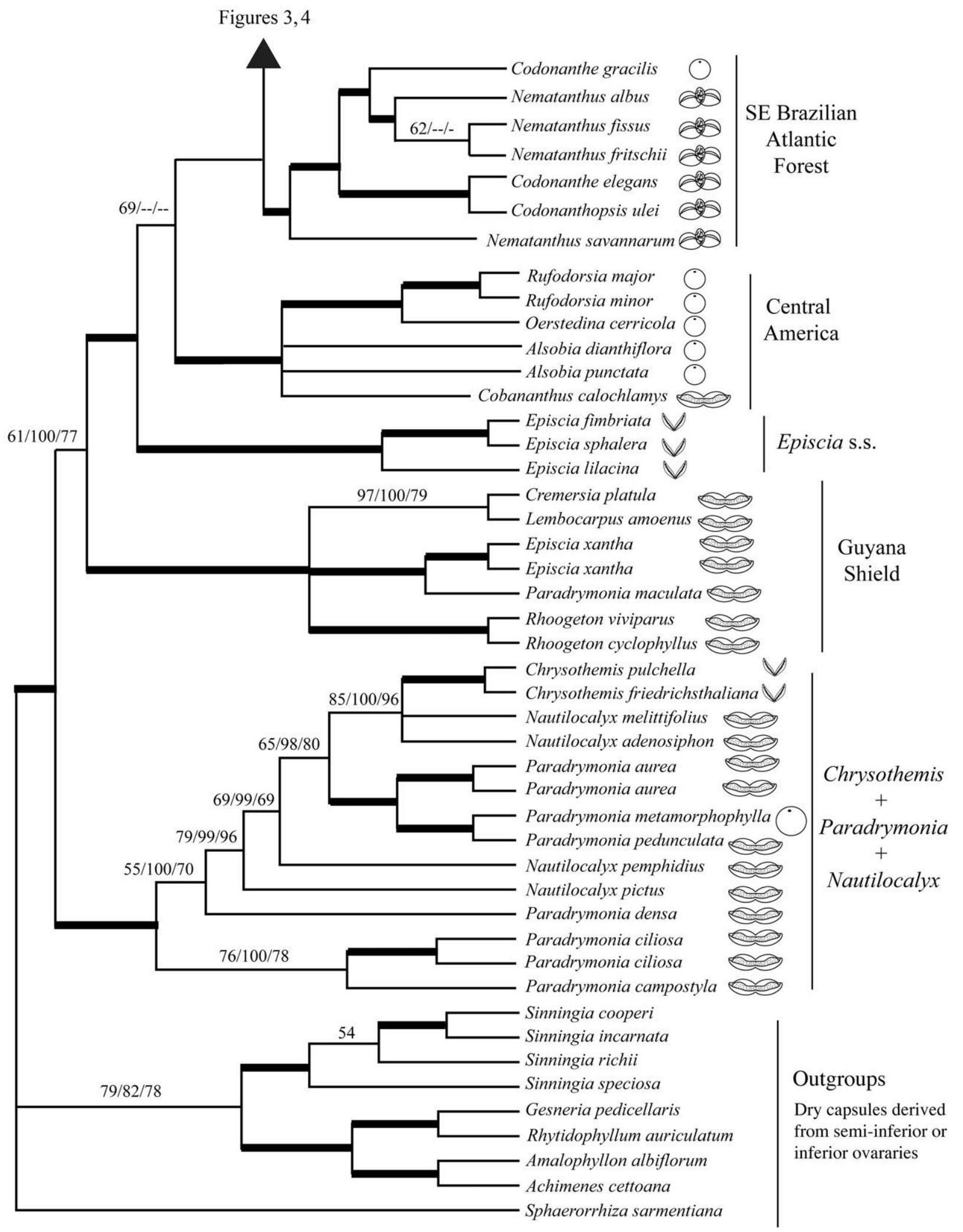

Fig. 2 Strict consensus tree from total evidence analysis of eight molecular markers (ITS, GCYC, ncp GS1, $n c p G S 2$, $t r n L$ intron, trnL-F spacer, rps16 intron, and rpl12-rps20 spacer). The strict consensus tree is from 48 most-parsimonious trees of 6411 steps. Numbers above branches are maximum parsimony (MP) bootstrap/maximum likelihood (ML) bootstrap/Bayesian inference (BI) posterior probabilities. Thick bars indicate nodes where support for all three analyses was $>95$. Note that the topology based on ML and BI is nearly identical. Incongruence between ML/BI and MP is explained in "Discussion" and is shown in figs. 5 and 6. Different fruit types are explained in detail in "Discussion" and are depicted using the images shown in the key in fig. 3 (i.e., dry capsules, semifleshy capsules, fleshy capsules, and indehiscent berries). 
phologies, the placement of E. xantha is more so because of the presence of stolons. The presence of stolons is found outside of Episcia in Gesnerioideae only in the genus Alsobia, whose species at times have been classified as Episcia. Leeuwenberg (1980) went so far as to include E. xantha within section Episcia and state that its closest relative was Episcia cupreata (Hook.) Hanst. An additional cultivated individual of E. xantha was included in this analysis to verify that the original material collected in French Guiana (J. F. Smith et al. 4116; app. A) was neither misidentified nor contaminated with other material. DNA from the two individuals was extracted, amplified, and sequenced years apart in time; therefore, the chances of contamination are minimal. The two individuals are maximally supported as monophyletic (figs. 2, 5). The fruits of E. xantha have been observed as dry dehiscent capsules. Leeuwenberg (1980) differentiated between globose and laterally compressed capsules when he described E. xantha and referred to most Episcia as globose (fig. $7 F$ ) and only E. xantha as laterally compressed (fig. 7E). The fruit of E. xantha is a dry capsule and therefore more similar to Lembocarpus (fig. $7 G$ ) than to the semifleshy capsules in Episcia (fig. $7 F$ ). The phylogenetic placement of E. xantha is not surprising given the convergence of stolons in multiple lineages, as discussed below.

A remarkable feature in $P$. maculata is an inflexed ventral corolla lobe that completely closes the opening of the tube (fig. 1B). The completely occluded throat was noted and illustrated by Hooker (1890). More recently, Feuillet (2009) described the inflexed ventral corolla lobe as a barrier mechanism that can be opened by exerting pressure on both sides of the apical third of the tube. Field observations for a doctoral dissertation by Hentrich (2008) noted that the corolla remained closed during the entire flowering period $(2 \mathrm{~d})$ and was forcibly opened by large euglossine bees (Eulaema sp.) by pulling down the petals.

The monospecific genus Lampadaria is not included in this analysis. There are few collections of Lampadaria rupestris Feuillet \& L. E. Skog, and it is known only from the PotaroSiparuni region of Guyana. The most recent collection is from 2001 by H. David Clarke (H. D. Clarke 8897, US). The elongate pedunculate and subcapitate inflorescence of Lampadaria are similar to Rhoogeton. In contrast, the capsular fruits of Lampadaria do not reflex at maturity, compared with the fully reflexed to nearly truncate bivalved capsules in Rhoogeton. The presence of inflorescence bracts was considered an important character by Feuillet and Skog (2003) to recognize Lampadaria as a member of the Episcieae, but this character may be overemphasized, as some genera that were thought to lack bracts (such as Resia) have been found to have bracts (e.g., the recently described species Resia bracteoides; Fernando-Alonso 2006; Skog and de Jesus 1997).

\section{Episcia s.s.}

In the Episcia s.s. clade, three species of Episcia are recovered as a monophyletic group that is strongly supported in all three analyses $(>95 \%)$. One difference between the MP and ML/BI is that this clade is sister to the primarily Central American clade (e.g., Alsobia, Rufodorsia, Oerstedina, and Cobananthus) in the MP/BI (fig. 2). The MP analysis suggests that Episcia is sister to the Central American clade, the Southeastern Brazilian Atlantic Forest clade, and the remaining genera shown in figure 3. The genus Episcia is not recovered as monophyletic in this analysis because of the position of E. xantha (discussed above), but the placement of the remainder of the genus here in the tribe is in agreement with previous phylogenetic analyses (Smith 2000b; Clark et al. 2006). The monophyly of Episcia has only been questioned previously depending on whether species of Alsobia, which also share the characteristic of stolons, are considered part of Episcia (Smith and Carroll 1997).

\section{Central American Clade}

The species recovered in the Central American clade are all native to Central America. This clade has been recovered as monophyletic in all other analyses that have sampled some or all of these genera (Smith and Carroll 1997; Smith 2000b; Zimmer et al. 2002; Clark and Zimmer 2003; Clark et al. 2006). The data here support the separation of Alsobia from Episcia. These two genera differ by the presence of one stolon per node and epiphytic habit in Alsobia as opposed to two stolons per node and terrestrial habit in Episcia (Wiehler 1983; Weber 2004). The same two leaf samples of Alsobia were included in Clark et al. (2006) and resulted in a monophyletic Alsobia with a $74 \%$ BS value. We recovered lower support for the monophyly of Alsobia, but this is likely because of the absence of an adequate sequence for $n c p G S 1$ for Alsobia punctata. Although this region amplified and was sequenced, it gave a result incongruent with other regions ( $A$. punctata sister to Cobananthus) and was therefore removed from the analyses, as it is likely a paralog.

The genus Rufodorsia was recently expanded to include one of the three traditionally recognized species of Oerstedina (Kriebel 2010) with the new combination Rufodorsia cerricola (Wiehler) Kriebel. The new combination published by Kriebel (2010) did not consider or discuss the other two species of Oerstedina (O. mexicana Wiehler and O. suffrutescens L. E. Skog), and therefore we have retained the name Oerstedina cerricola. Wiehler $(1975 b)$ differentiated Oerstedina from Rufodorsia by relatively larger corollas that lack red coloration on the dorsal surface and the presence of pointed berries in contrast to globose berries. These differences are consistent for differentiating these two genera. These two clades share a recent common ancestor, and the recognition of two separate genera or the reduction of the genus Oerstedina in Rufodorsia should be considered in the context of future phylogenetic and monographic work of Central American Gesneriaceae. The sister-group relationship of Oerstedina and Rufodorsia is strongly supported in this study and in previous phylogenetic analyses (Smith 2000b; Clark et al. 2006).

\section{Convergence of Stolons}

The presence of stolons in the Gesneriaceae is known only in Episcia and Alsobia. The data presented here and in Clark et al. (2006) strongly support that the majority of Episcia species form a monophyletic group that is not sister to any other single genus of Episcieae. Clearly, the presence of sto- 
lons is convergent on the basis of the placement of these two genera in previous and the current phylogenetic analyses (figs. 3, 6). The stolons in Alsobia are produced one per node in alternating leaf axils. The successive stolons give the appearance of a single pendent stem (Wiehler 1983). In contrast, the stolons in Episcia are produced in pairs at each node (Wiehler 1983; Weber 2004). In this analysis, the placement of E. xantha is supported as an additional clade that has evolved stolons separate from traditional Episcia (fig. 2). Thus, the distinguishing traits of terrestrial habit with two stolons per node is convergent in "Episcia" xantha and other species of Episcia.

\section{Southeastern Brazilian Atlantic Forest Clade}

Members of the Southeastern Brazilian Atlantic Forest clade are widespread in the New World but are most diverse in the Atlantic Forest of southeastern Brazil. Members of this clade are mostly unique in Episcieae in that they have haploid chromosome counts of $n=8$ rather than $n=9$, which is otherwise found throughout the tribe. The exception to this is Codonanthopsis dissimulata, which has been reported as $n=9$ (Wiehler 1978). Nematanthus savannarum was recently transferred from Alloplectus (Clark 2005), and its chromosome count is not known. Other than chromosome counts, there are no other nonmolecular traits that define this clade. This clade has been recovered as monophyletic in previous analyses of Episcieae, although sampling has varied widely (Smith 2000b; Clark et al. 2006).

Both this study and Clark et al. (2006) failed to recover a monophyletic Codonanthe, although there is no overlap in species sampling. Codonanthe gracilis, which falls amid the Brazilian Nematanthus species, is also from Brazil, as is Codonanthe carnosa, which Clark et al. (2006) also found to be part of the Nematanthus clade. The other species of Codonanthe sampled here and by Clark et al. (2006) are species not found in Brazil. Further sampling of both Brazilian and non-Brazilian species will be essential for evaluating generic boundaries for Codonanthe, Codonanthopsis, and Nematanthus and is the current focus of research by Alain Chautems and collaborators.

Clark (2005) transferred the taxon and published the combination N. savannarum (C. V. Morton) J. L. Clark from Alloplectus savannarum as a best fit for a species whose inclusion in Alloplectus was clearly in error. Its placement in Nematanthus was uncertain, as it occurs in the Guyana Shield and is disjunct from the remainder of Nematanthus, which occur in southeastern Brazil. This species was not supported as sister to Nematanthus by Clark et al. (2006), but it is strongly supported as the sister to all other members of this clade in the current analysis, making its inclusion in Nematanthus less supported. It is likely that this species represents yet another monospecific genus from the Guyana Shield, but one that is not part of the clade recognized here as the Guyana Shield (fig. 2). Here again there is a convergence of several morphological characters-such as tubular corolla shape, fleshy capsular fruits, and epiphytic habitthat caused this species to be initially described in Alloplectus (Morton 1948).

\section{The Alloplectus/Columnea/Drymonia Alliance (Figs. 3, 4, 6)}

The Alloplectus/Columnea/Drymonia clade is well supported (100/97/100), and, with the exception of Drymonia, all of the genera are well supported. Beyond the grade of Crantzia, Corytoplectus, and Neomortonia nummularia, there is little support for resolution among the genera (fig. 3). Most of these genera have been recovered as monophyletic in previous studies (Smith 2000b; Zimmer et al. 2002; Clark et al. 2006), but with little support for intergeneric relationships.

Outside of Paradrymonia, this clade has faced some of the most difficult challenges with respect to generic delimitations. As a result of extensive taxon sampling by Clark and colleagues (Clark and Zimmer 2003; Clark 2005, 2009; Clark et al. 2006), most of these genera have been resolved fairly recently by identifying monophyletic lineages in an otherwise polyphyletic Alloplectus that resulted in the resurrection of Crantzia and Glossoloma and the transfer of A. savannarum to Nematanthus. As with previous studies (Smith 2000b; Clark et al. 2006), the monophyly of Columnea as a single genus rather than five is supported here, and with a revised circumscription of Drymonia (sensu Clark et al. 2006) this genus is also monophyletic.

Further relationships among genera will be discussed below on the basis of the reduced analysis.

\section{The Reduced Analysis: Alloplectus/ Columnea/Drymonia Alliance}

Glossoloma is strongly supported as sister to Columnea (93/92/100; fig. 4). Resolving these two genera as sister will be critical to further resolve phylogenetic relationships within Columnea, which is the largest Neotropical genus of Gesneriaceae in terms of its total number of species (J. F. Smith, M. T. Ooi, L. J. Schulte, M. Amaya Marquez, R. Pritchard, and J. L. Clark, unpublished manuscript). Likewise, the placement of Neomortonia rosea (figs. 2, 4, 5) as sister to the sampled species of Drymonia will be important as future studies investigate the evolutionary relationships of this latter genus (L. Clavijo, personal communication). Last, these data resolve Alloplectus as sister to all of the aforementioned genera with moderate $(\mathrm{MPBS}=78, \mathrm{MLBS}=70)$ to strong $(\mathrm{PP}=100)$ support (fig. 4). Only a single species of Alloplectus was sampled here, and it may be that the inclusion of additional species would have stabilized this relationship with greater support.

This study provides additional support and evidence for the nonmonophyly of Neomortonia. Although early studies that included both species of this genus failed to recover a monophyletic group (Clark and Zimmer 2003), low support and relative proximity of the two species in the tree led to uncertainty about the nonmonophyly of the genus. This uncertainty was increased when Neomortonia was recovered as monophyletic by Clark et al. (2006); however, the two species were in a single clade with the inclusion of morphological data-molecular data alone failed to bring the two species together (J. L. Clark, unpublished results). Although the corollas of the two species are dramatically different (fig. 


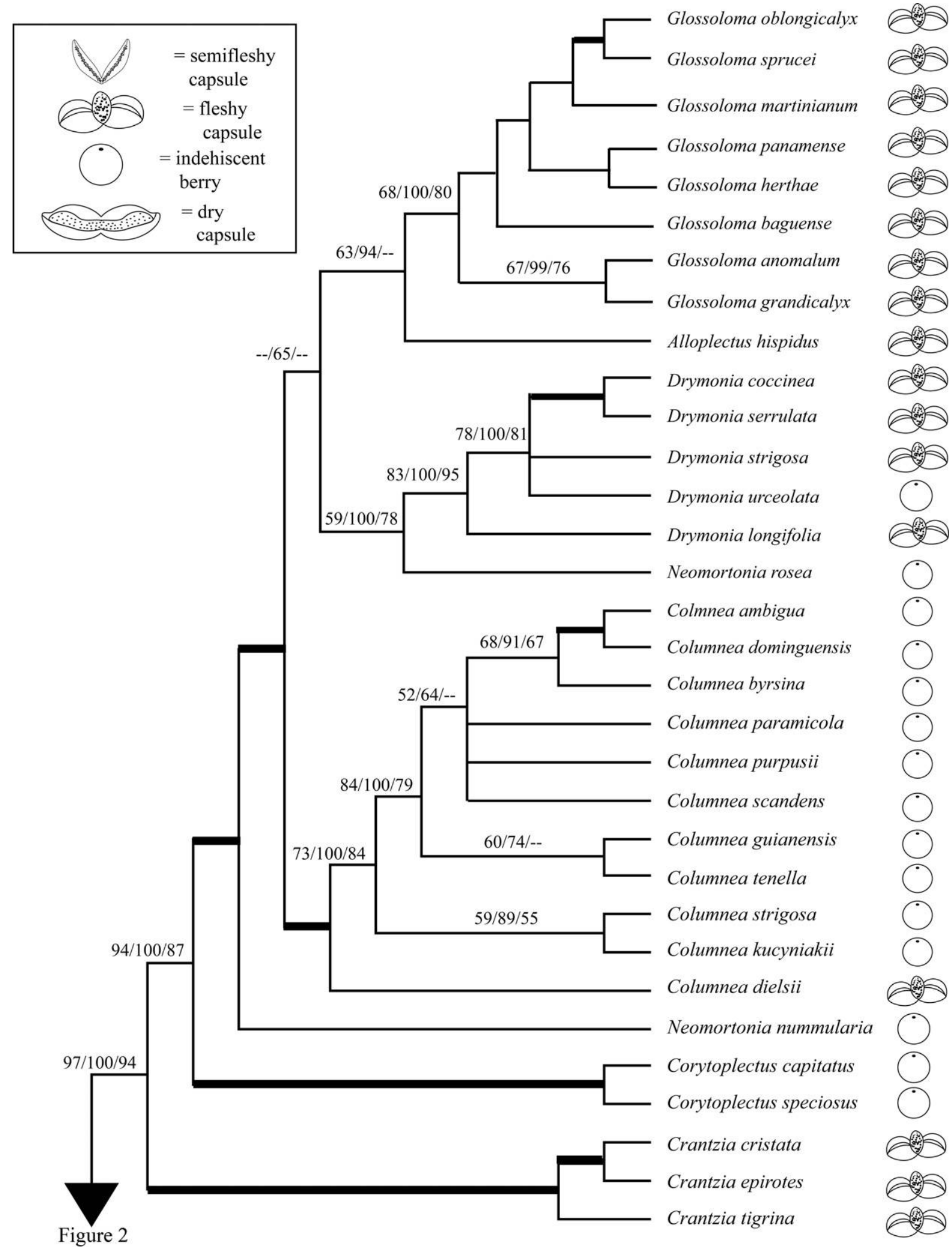

Fig. 3 Alloplectus/Columnea/Drymonia clade. See the fig. 2 legend for details. 


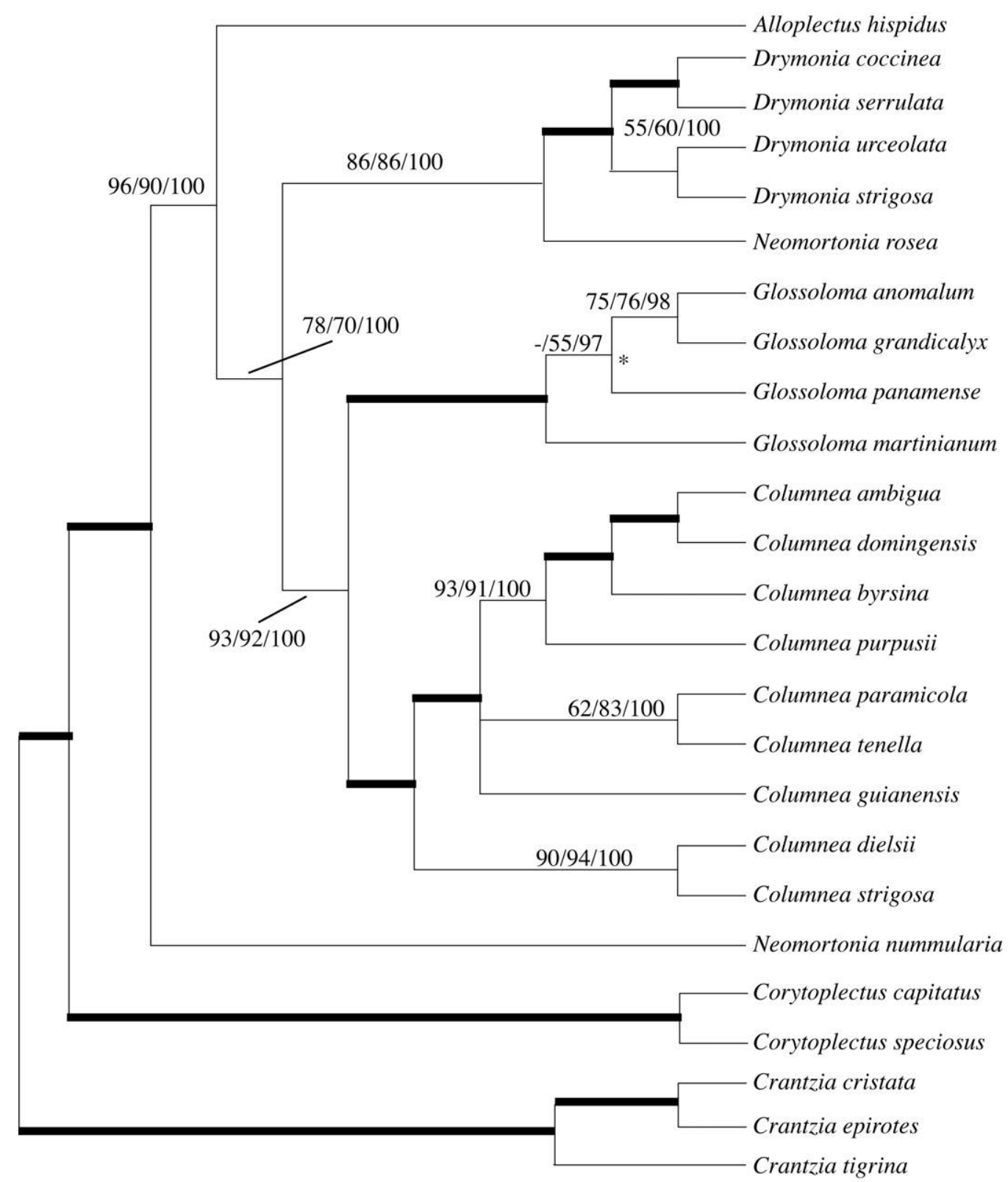

Fig. 4 Summary of maximum likelihood ( $-\ln$ likelihood $=28,400.094556)$, strict consensus of maximum parsimony analysis, and majorityrule Bayesian inference topology for reduced clade (25 taxa) based on 13 molecular markers (ITS, GCYC, ncpGS1, ncpGS2, trnL intron, trnL-F spacer, $r p s 16$ intron, rpl12-rps20 spacer, $r p l 32-t r n L$ spacer, $\operatorname{trn} Q-r p s 16$ spacer, $\operatorname{trn} D-T$ spacer, PepC intron, and trnS-G spacer). Asterisks (*) indicate nodes that collapse in the strict consensus of the maximum parsimony analysis of two trees of length 2262 (consistency index $=0.57$, retention index $=0.67$, rescaled consistency index $=0.56)$. The topology from the Bayesian analysis using either a single model or different models for each of the data partitions resulted in the same topology. Numbers above branches are maximum parsimony bootstrap/maximum likelihood bootstrap/Bayesian inference posterior probabilities. Thick bars indicate nodes where support for all three analyses was $>95$.

$1 E, 1 F)$, they both have an indehiscent fleshy orange berries (fig. 1C, 1D). See the section below for further discussion of the convergence of berries in traditional Neomortonia. Here, for the first time, there is strong support for the placement of N. rosea as sister to Drymonia (86/86/100) and for N. nummularia as sister to the majority of the genera in this clade except Corytoplectus and Crantzia (fig. 4). The type for the genus is $N$. rosea, meaning that a new generic name is necessary for N. nummularia.
The strong support for the monophyly of this clade and the strong support for the placement of Crantzia as sister to the remainder of this clade allowed for further sampling of DNA regions within each of these genera and the use of a fewer number of outgroups. This can be especially critical when attempting to resolve relationships at the species level, as more rapidly evolving DNA regions will be essential to provide sufficient data. The inclusion of more distant outgroups could result in excessive homoplasy in the analysis or 


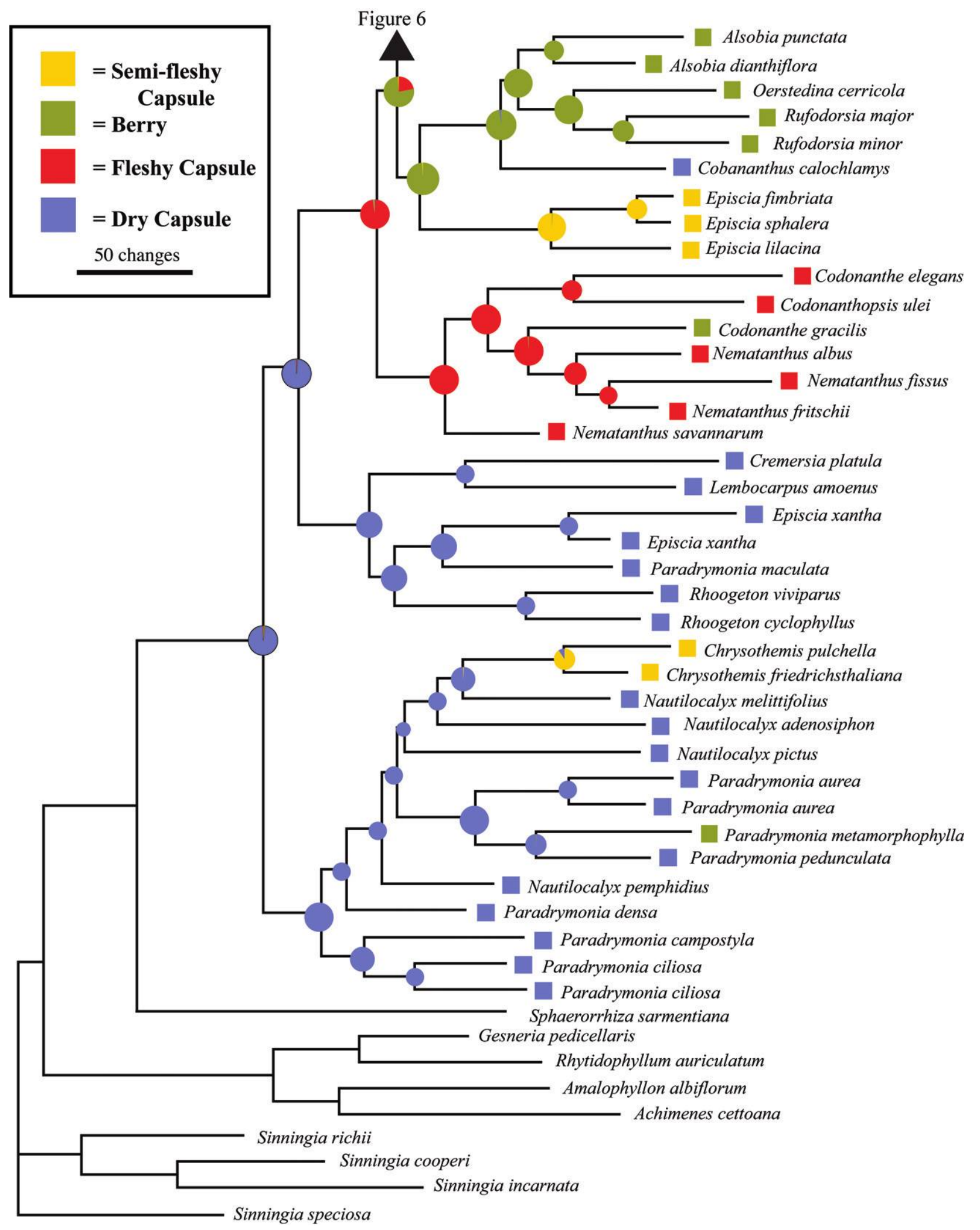

Fig. 5 Stochastic character mapping of fruit types using the 50\% majority-rule tree generated from Bayesian inference (BI) of eight molecular markers (ITS, GCYC, $n c p G S 1$, ncp GS2, $\operatorname{trnL}$ intron, $\operatorname{trnL}-F$ spacer, $r p s 16$ intron, and $r p l 12-r p s 20$ spacer). Pie charts represent ancestral states at each node that were calculated as the marginal posterior probability of each possible character state. Note that the BI and maximum likelihood topologies are congruent. 


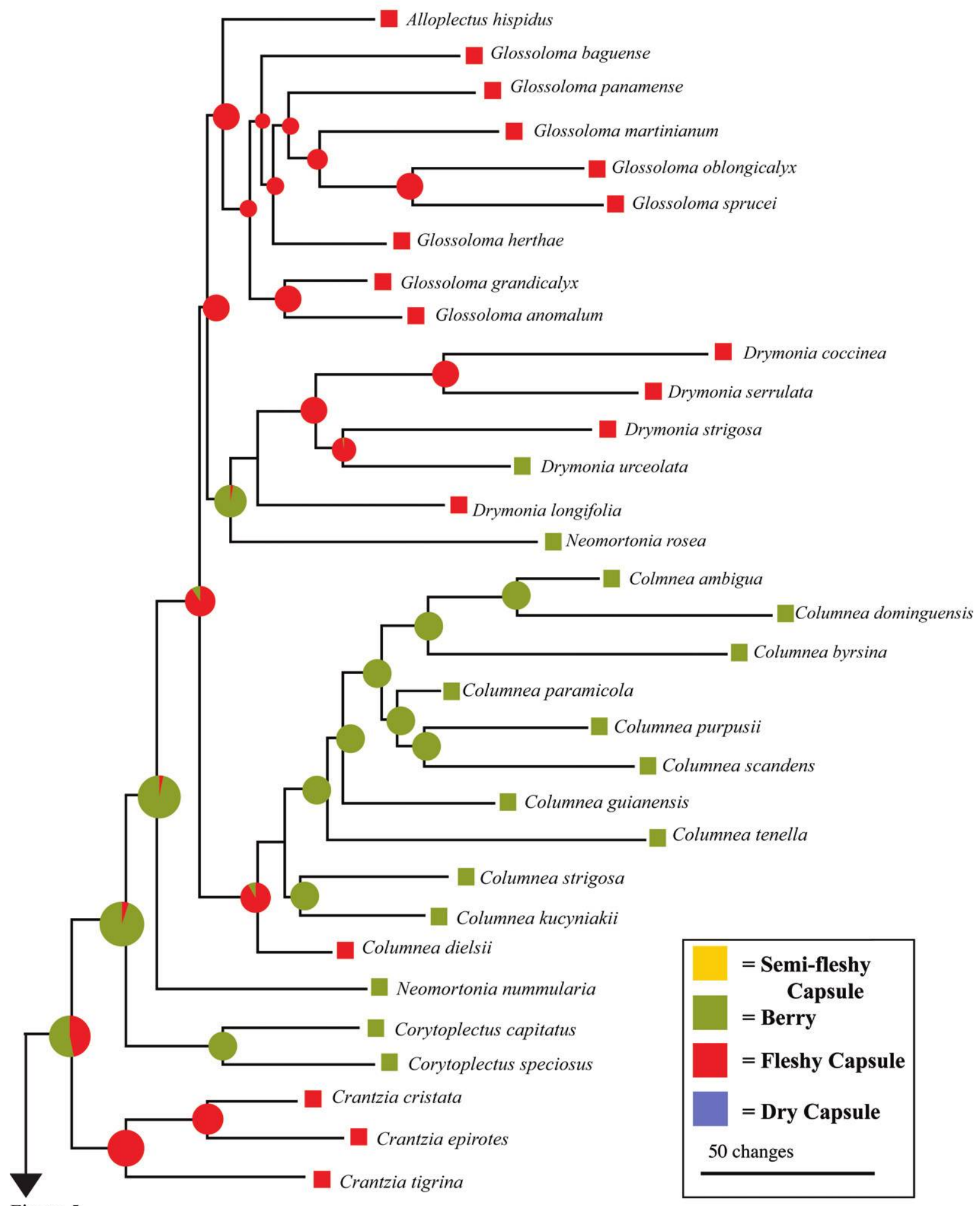

Figure 5

Fig. 6 See the fig. 5 legend for details. 
limit the ability to unambiguously align sequences. For example, the use of Glossoloma alone as the outgroup for Columnea has permitted the use of some rapidly evolving low-copy nuclear genes to resolve species-level relationships within the genus without compromising the ability to assess homology accurately across all taxa (J. F. Smith, unpublished results).

\section{Evolution of Fleshy Display Capsules, Semifleshy Capsules, and Berries}

Our results strongly support two independent origins of fleshy fruits (figs. 2, 3, 5). It should be noted that fleshy fruits are defined here as indehiscent berries (figs. $1 \mathrm{C}, 1 \mathrm{D}, 1 \mathrm{G}, 1 \mathrm{H}$, $7 C$ ) or fleshy display capsules (figs. $1 I, 7 A, 7 B$ ). The bivalved capsules of semifleshy fruits typically open to $45^{\circ}$, and the valves are not reflexed or showy (fig. $7 D, 7 H$ ). Fleshy capsules (figs. $1 I, 7 A, 7 B$ ) are fully reflexed at maturity and contrast in color with an erect cone-shaped mass of seeds embedded in brightly colored funiculi. The seeds are sometimes clumped together (fig. $1 I$ ) or remain attached to the septum of reflexed valves (fig. $7 A, 7 B$ ). Fleshy capsules are often referred to as display capsules because of their contrasting color and putative role in attracting animals that eat them, resulting in seed dispersal. Reports of the role in seed dispersal from display capsules include fruit-eating bats, birds, and possibly monkeys (Wiehler 1983). Use of parsimony to map fruit character states demonstrates a clear transition to fleshy fruits prior to the divergence of the Central American clade (fig. 2) with a single reversal to dry capsule in Cobananthus. The second origin is the berry fruit of Paradrymonia metamorphophylla (fig. 2). The ML/BI topology differs from the MP tree in the positions of the Episcia s.s., Central American, and Southeastern Brazilian Atlantic Forest clades, but using stochastic mapping we also show two clear origins of fleshy fruits (fig. 5). There is a 99\% posterior probability of fleshy fruits at the node prior to the divergence of the Southeastern Brazilian Atlantic Forest clade (97.5\% fleshy capsule, $1.5 \%$ berry; app. B, available in the online edition of the International Journal of Plant Sciences). The ML/BI topology places the Episcia s.s. clade as sister to the Central American clade, and at this node there is still a greater posterior probability of reconstructing the ancestral state as fleshy (fig. 5). As with MP, there is a second origin of fleshy fruits with the presence of a berry in P. metamorphophylla (fig. 5). If we interpret fleshiness even more broadly to include the semifleshy capsules, then both MP and stochastic mapping would indicate a third origin of fleshiness in Chrysothemis (figs. 2, 5).

Fleshy fruits, whether berries or capsules, is a synapomorphy that defines clades with high diversity in the Andes, Central America, and southeastern Brazil. In contrast, Paradrymonia and Nautilocalyx are defined by the presence of semifleshy capsules and are mostly found in the Guiana Shield of northwestern South America and the foothills of the eastern slopes of the Andes. There are exceptions to this trend. For example, two species of Chrysothemis (fig. 5) are common in Central America, and they share a recent ancestor with Nautilocalyx melittifolius from the Caribbean. The sister taxon to Chrysothemis (2 spp.) and N. melittifolius is Nautilocalyx adenosiphon from French Guiana. Taxon sam- pling for Nautilocalyx and Paradrymonia is biased from collections that were made in South and Central America because of the geographic focus from extensive fieldwork by the first author. Taxon sampling for species native to northwestern South America (especially Venezuela) are limited to material readily available in cultivation.

Our results strongly support independent origins of berries in at least seven clades, regardless of the methods used to map ancestral character states (figs. 2, 3, 5). There are three independent origins in clades that otherwise are characterized by dehiscent fruits (P. metamorphophylla, C. gracilis, and Drymonia urceolata). Two other origins of berries can be mapped at lower levels in the topologies and include the ancestor of the Central American clade (figs. 2, 5) and species of Columnea other than C. dielsii (figs. 3, 6). The MP and stochastic mapping differ in the final origins of berries. Parsimony is equivocal on the ancestral state of the $N$. roseal Drymonia clade (fig. 3), implying a potentially independent origin of a berry in N. rosea. Stochastic mapping clearly indicates that the ancestor to the $N$. rosea/Drymonia clade is a berry (fig. 6), but the ancestor to Drymonia as a whole is clearly a fleshy capsule (fig. 6). Although the placement of the ancestral state differs between the two analyses, there are still two independent origins of berries. The MP mapping is equivocal on whether the ancestor to the Alloplectus/ Columnea/Drymonia clade is a berry or fleshy capsule, potentially giving rise to two origins of berries independently in N. nummularia and Corytoplectus (fig. 3), bringing the total independent origins of berries to eight with parsimony. Stochastic mapping, on the other hand, indicates that the ancestor to the Alloplectus/Columnea/Drymonia clade and the Central American/Episcia s.s. clade has a greater probability of being a berry (fig. 5) and a slightly greater probability as the ancestral state to the Alloplectus/Columnea/Drymonia clade itself (fig. 6). This implies that N. nummularia and Corytoplectus berries have a single ancestral origin and would imply seven independent origins of berries. The convergence of berries in the Gesneriaceae has been documented in previous phylogenies (Smith 2000a; Clark et al. 2006), but not with strong support and not with as many independent origins.

This is the first phylogeny that strongly supports the nonmonophyly of traditionally recognized Neomortonia. Wiehler (1975a) defined Neomortonia by the presence of brightorange berries that appear laterally compressed (fig. 1D). Further investigation of $N$. nummularia from recent fieldwork in Ecuador has documented that the berries are more globose and not laterally compressed, as reported by Wiehler (1975a; fig. 1C). The only character that traditional Neomortonia share in common is that both berries are bright orange (fig. 1C, 1D). The corollas of these two species are very different, with $N$. rosea having a hypocyrtoid or pouched corolla (fig. $1 E$ ) and $N$. rosea having a campulate corolla with fimbriate margins (fig. $1 F$ ). The morphologically divergent corollas, different berry shape, and phylogenetic results presented here warrant the separation of this polyphyletic genus.

It should be noted that Columnea is traditionally defined by the presence of an indehiscent fleshy berry (fig. $1 \mathrm{G}, 1 \mathrm{H}$ ). There are only two known exceptions where Columnea has a fleshy capsule, and both are basal members of the clade. Columnea dielsii and an undescribed species from Peru have 


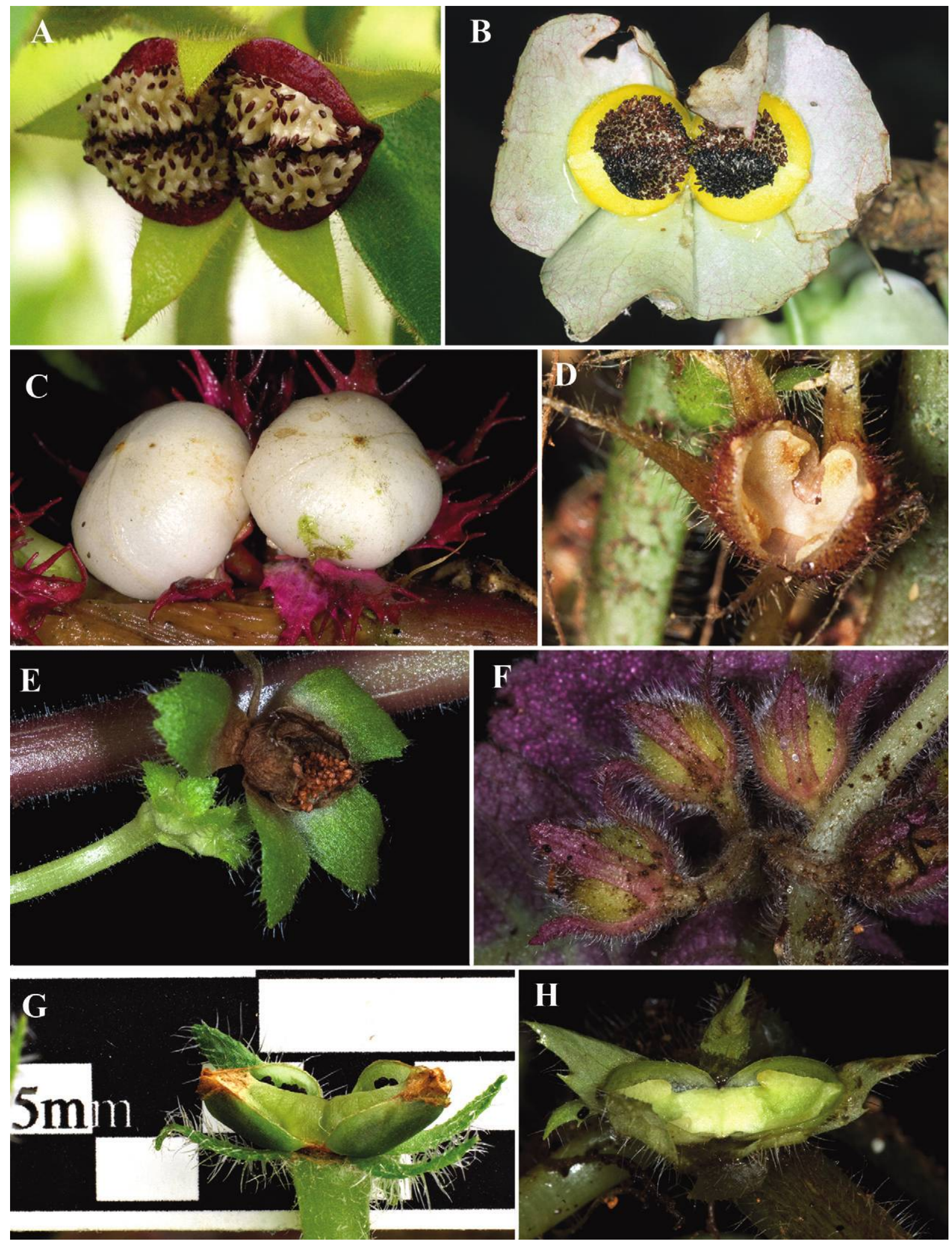

Fig. 7 Variation in fruits in Episcieae. A, Fleshy display capsule in Nematanthus albus. B, Fleshy display capsule in Drymonia chiribogana. C, Indehiscent fleshy berry in Paradrymonia metamorphophylla. D, Semifleshy capsule in Paradrymonia ciliosa. E, Dry capsule in Episcia xantha. F, Semifleshy capsule in Episcia lilacina. G, Dry capsule showing splash-cup seed dispersal in Lembocarpus amoenus. H, Semifleshy capsule in Nautilocalyx panamensis. (Voucher specimens at US: B, J. L. Clark 7358; C, J. L. Clark 9874; D, J. L. Clark 6791; E, J. L. Clark 11323 ; F, J. L. Clark 1259; G, J. L. Clark 8841; H, J. L. Clark 12735. Photos: A by Jiri R. Haager, B-G by John L. Clark, and H by James F. Di Loreto.) 
fleshy capsules that are similar to Glossoloma, and the former is shown to be the sister taxon to all other Columnea (figs. 3, 6). The undescribed species from Peru was included in Clark et al. (2006) as Columnea sp. nov. (J. L. Clark 8188 , US) and was shown to be a basal member of Columnea. Focused fieldwork to assess fruit morphology is necessary to verify whether other basal members of Columnea have fleshy capsules. For example, Columnea bypocyrtantha is reported as having a berry by Smith (1994), but the illustration of the fruits (fig. 6 in Smith 1994) appears laterally compressed, and the seeds were noted as not observed in the description. It should be noted that other basal members of Columnea-C. strigosa and C. kucyniakii-have fleshy indehiscent berries and not fleshy capsules.

Two independent origins of berries are strongly supported in P. metamorphophylla and D. urceolata. These two species are strongly supported in clades that are mostly defined by the presence of capsules. Thus, indehiscent berries is autapomorphic in P. metamorphophylla and synapomorphic within Drymonia. Both of these taxa have been collected on numerous occasions, and sequences have been obtained from independent extractions. The berry of $P$. metamorphophylla is bright white and globose (fig. 7C), and it is the only known species in Paradrymonia and closely related genera (e.g., Nautilocalyx and Chrysothemis) that lack semisucculent capsules. The berry of D. urceolata is pointy and light green. Clark et al. (2006) showed that D. urceolata shared a recent common ancestor with Drymonia turrialvae and D. ambonensis (not sampled here), which also have berries.

Accurate assessment of fruit morphology based on herbarium specimens in the Episcieae is challenging because their fruits are fleshy and are often destroyed when pressed and dried. Many descriptions and flora treatments have inaccurate or inadequate descriptions of fruit morphology. Additionally, fruits are often difficult to locate in the field because they are presumably rapidly consumed by dispersers, in contrast to frequently collected specimens with showy persistent flowers. As a result, fruit variation in the Episcieae is poorly documented relative to variation in flowers, and future studies will likely discover additional taxa with fleshy berries in the Episcieae that are presumed to have fleshy or dry capsules.

\section{Dry Fruits, Splash-Cup Seed Dispersal, and Terrestrial Herbs}

The presence of splash-cup seed dispersal is an important feature that needs to be explored in the basal lineages of the Episcieae. Habit is also important, as many species are described on the basis of herbarium specimens. Further evaluation of these two traits may suggest that they are correlated and underreported in the literature.

One trait that is often overlooked when evaluating epiphytic or terrestrial habit is the designation of a species as facultative epiphyte, obligate epiphyte, or obligate terrestrial. It should be noted that a combination of these characters is necessary to describe some species. Fieldwork is essential for assessing habit, because herbarium specimens represent only one stage in the life cycle of the plant. For example, Paradrymonia ciliosa is an elongate climber when immature and then develops into an epiphyte with a basal rosette of leaves when mature. Thus, the mature stage appears as an obligate epiphyte. The presence of an obligate or primarily terrestrial habit in the Episcieae is especially challenging to determine when the plants are herbs (i.e., nonshrubs, as in many of the unbranched shrubs found in Glossoloma).

A majority of the species in the tribe Episcieae are epiphytic. The Guiana Shield clade is exceptional for the Episcieae in being comprised of nonfacultative terrestrial (i.e., obligate) herbs. The known exception is $P$. maculata, which is described as being epiphytic or terrestrial (Skog and Feuillet 2008; Feuillet 2009). A feature that many of the species in the Guiana Shield clade have in common is dry dehiscent capsules with fully reflexed valves at maturity (e.g., L. amoenus; fig. 7G). It is possible that these dry dehiscent fruits employ a mechanism of seed dispersal from splashing caused by rainfall. This combination is also associated with smaller seeds and may be associated with carriage on the feet of animals (Burtt 1970, 1976). Capsules that are reported to have splash-cup seed dispersal represented in the Guiana Shield clade are Lembocarpus, Cremersia, and Rhoogeton (J. Ertelt, unpublished manuscript).

Many of the species in Chrysothemis, Paradrymonia, and Nautilocalyx that are epiphytic (e.g., P. metamorphophylla) have berries or capsules. In contrast, obligate terrestrial herbs, such as Nautilocalyx panamensis, have dry capsules that appear to be splash-cup dispersed (fig. $7 H$ ). One of the challenges for understanding and evaluating character states is that we do not have ready access to fruits or fruit images for many members in these clades, where fruits are described as subglobose, conical, succulent, or semisucculent. It was surprising to discover that P. metamorphophylla (fig. 7C) is a berry because it is autapomorphic in a clade that is entirely capsular. Future research may discover that other species in this clade are also indehiscent berries. Future evaluation of habit and fruit morphology will allow for the correlation between obligate terrestrial habit and the presence of splashcup seed dispersal.

\section{Assessing Fruit Types for Future Studies}

Information on fruit types can be challenging to obtain. Many fruits in closely related tribes are dry capsules that are derived from semi-inferior ovaries (Diastema, Monopyle, Gesneria, Rhytidophyllum, etc.). The relative succulence of fruits in the Episcieae is variable and usually oversimplified in the literature. For example, when the fruits of Episcia (fig. $7 F$ ) are compared with those of Gloxinieae (e.g., Diastema or Monopyle), they would easily be described as succulent (Skog 1978; Weber 2004). When the fruits of Episcia are compared with those of Drymonia, they are relatively dry. Likewise, the fruits of many species of Chrysothemis, Nautiloclayx, and Paradrymonia are described as succulent in the literature. One of the challenges of assessing fruit types in this study was critically evaluating the character states assigned to fruits. For example, Chrysothemis is described as a succulent globose capsule by Weber (2004). In contrast, an illustration of Chrysothemis friedrichsthaliana Wiehler (2002) suggests that the capsule is conical and dry. 


\section{Utility of DNA Regions: Does It Take 14 Tortoises to Make One Hare?}

It has been a challenge to find DNA regions that provide sufficient variability without excessive homoplasy or paralogy to resolve relationships among the Gesneriaceae and provide strong support for that resolution. Despite initial attempts to rely on single regions, the multigene approach has become the standard for molecular systematics in the family (Möller and Cronk 1997; Smith et al. 1997, 2004a, 2004b; Smith 2000b; Zimmer et al. 2002; Mayer et al. 2003; Perret et al. 2003; Roalson et al. 2005a, 2005b, 2008; Clark et al. 2006; Möller et al. 2009; Wang et al. 2011; Woo et al. 2011). For example, all the major genera were supported in the reduced and full analysis, but it was not until additional genic regions were added in the reduced analysis that a phylogeny was produced with a strongly supported placement of Alloplectus hispidus as sister to Drymonia + N. rosea + Glossoloma + Columnea (fig. 4). In contrast, the expanded analysis of fewer base pairs had little support for A. hispidus as the sister taxon to Glossoloma (figs. 3, 6). Despite recovering more than $25 \%$ of the characters as potentially phylogenetically informative in the full analysis, the eight loci were insufficient to fully resolve and provide support for relationships across all of Episcieae, most notably among the members of the Alloplectus/Columneal Drymonia (fig. 4). An additional six regions were added to improve resolution among the genera of this clade, sampling from regions that have been considered rapidly evolving (Malcomber 2002; Shaw et al. 2007). However, these 14 combined regions, with more than 8000 aligned base pairs, yielded only $\sim 5 \%$ of the characters as phylogenetically informative. In part this is attributable to the retention of several loci that contributed little to the resolution of this clade (e.g., trnL-F, trnL intron), and had these sequences not already been obtained for the members of this clade, it is unlikely that they would have been sequenced to improve resolution. Nevertheless, the $\sim 400$ bp of potentially phylogenetically informative characters were able to fully resolve and provide strong support for the intergeneric relationships in the Alloplectus/Columnea/Drymonia clade in the reduced analysis (fig. 4). These results are similar to those of Miller et al. (2009), where nine noncoding cpDNA regions were screened for utility to resolve relationships within Solanaceae; three were discovered to have particularly strong utility, whereas another three provided little in the analysis. We likewise would advocate screening of sequence data prior to a larger-scale analysis at the species level and would advocate the inclusion of $r p l 32-t r n L, \operatorname{trn} Q-$ $r p s 16$, trnH-psbA, and ITS for further investigation among species in Gesneriaceae.

\section{Acknowledgments}

We thank Tom Croat, Chris Davidson, Laurence E. Skog, Marisol Amaya Marquez, and Armando Rincon for sharing leaf material of Gesneriaceae. We thank the Biological Diversity of the Guiana Shield Program (Smithsonian Institution's Department of Botany) for providing ongoing support through specimen data, images, and tissue samples. This study was supported by grants from the National Science Foundation (DEB-0949270 to J. F. Smith and J. L. Clark, DEB-0841958 to J. L. Clark, and DEB-0107763 to J. F. Smith) and the Marjorie Moore Davidson Foundation (to J. F. Smith). We thank Jiri R. Haager (Teplice Botanical Garden, Czech Republic) and James F. Di Loreto (Smithsonian Institution's Photographic Services) for providing fruit images. We are especially grateful to Reata Strickland, creative director for special projects from the University of Alabama's Office of Academic Affairs, for guidance in preparing and creating the illustrations.

\section{Appendix A}

\section{Voucher Information}

Provided here are species included in the analyses, voucher information, and GenBank accession numbers for ITS, GCYC, ncpGS1, ncpGS2, trnL intron, trnL-F, rps16 intron, rpl12-rps20, rpl32-trnL, trnQ-rps16, trnD-T, PepC, trnS-G, and trnH$p s b A$. Unvouchered samples taken from live material growing at the Smithsonian's U.S. Botany Research Greenhouses (USBRG) are designated by their live accession number. Sequences not obtained are designated by a dash (-), sequences not applicable to the analyses are designated by "NA," and generic type species are designated with an asterisk ("). Herbarium acronyms follow Thiers (2011).

Taxon; voucher and herbarium; locality; ITS, GCYC, ncpGS1, ncpGS2, trnL intron, trnL-F spacer, rps16 intron, rpl12rps20 spacer, rpl32-trnL spacer, $\operatorname{trn} Q-r p s 16$ spacer, $t r n D-T$ spacer, PepC intron, $t r n S-G$ spacer.

\section{Ingroup}

Alloplectus hispidus (Kunth) Mart.; J. L. Clark 7720 (US); Ecuador; DQ211111, JQ953835, JQ954073, JQ953724, JQ954233, JQ953896, JQ954137, JQ953984, JQ953960, JQ954208, JQ953811, JQ954048, JQ953700.

Alsobia dianthiflora (H. E. Moore \& R. G. Wilson) Wiehler; J. Hall s.n. (SEL); cultivated (Costa Rica); DQ211160, JQ953837, JQ954074, JQ953726, JQ954235, JQ953898, JQ954139, JQ953986, NA, NA, NA, NA, NA. Alsobia punctata (Lindl.) Hanst.*; J. L. Clark 8851 (US); cultivated (Mexico); DQ211159, JQ953836, —, JQ953725, JQ954234, JQ953897, JQ954138, JQ953985, NA, NA, NA, NA, NA. 
Chrysothemis friedrichstaliana (Hanst.) H. E. Moore; M. Amaya M. 532 (COL); Colombia; JQ953786, JQ953839, JQ954076, JQ953728, JQ954237, JQ953900, JQ954141, JQ953988, NA, NA, NA, NA, NA. Chrysothemis pulchella (Donn ex Sims) Decne."; J. L. Clark 8864 (US); South and Central America; AY047085, JQ953838, JQ954075, JQ953727, JQ954236, JQ953899, JQ954140, JQ953987, NA, NA, NA, NA, NA.

Cobananthus calochlamys (Donn. Sm.) Wiehler"; J. L. Clark 5613 (US); cultivated (Guatemala); AF543273, JQ953840, JQ954077, JQ953729, JQ954238, JQ953901, JQ954142, JQ953989, NA, NA, NA, NA, NA.

Codonanthe elegans Wiehler; J. F. Smith 3932 (SRP); cultivated (Belize); JQ953787, AY363929, JQ954078, JQ953730, JQ954239, JQ953902, JQ954143, JQ953990, NA, NA, NA, NA, NA. Codonanthe gracilis (Mart.) Hanst.; J. F. Smith 3721 (SRP); cultivated (Brazil); JQ953788, JQ953841, JQ954079, JQ953731, JQ954240, JQ953903, JQ954144, JQ953991, NA, NA, NA, NA, NA.

Codonanthopsis ulei Mansf.*; J. L. Clark 8868 (US); cultivated (Brazil); DQ211167, JQ953842, JQ954080, JQ953732, JQ954241, JQ953904, JQ954145, JQ953992, NA, NA, NA, NA, NA.

Columnea ambigua (Urb.) B. D. Morley; J. F. Smith 3701 (SRP); Puerto Rico; JQ953789, JQ953843, JQ954081, JQ953733, JQ954242, JQ953905, JQ954146, JQ953993, JQ953974, JQ954222, JQ953824, JQ954061, JQ953713. Columnea byrsina (Wiehler) L. P. Kvist \& L. E. Skog; J. F. Smith 3408 (SRP); Colombia and Ecuador; AF272176/AF272177, AY363931, AY623214, AY623259, AY364304, AY364304，JQ954147，AY623365，JQ953975，JQ954223，JQ953825, JQ954062, JQ953714. Columnea dielsii Mansf.; J. L. Clark 5813 (US); Ecuador; AF543250, JQ953844, JQ954082, JQ953734, JQ954243, JQ953906, JQ954148, JQ953994, JQ953980, JQ954229, JQ953831, JQ954068, JQ953844. Columnea domingensis (Urb.) B. D. Morley; L. Hahn 495 (SRP); Dominican Republic; JQ953790, JQ953845, -, JQ953735, JQ954244, JQ953907, JQ954149, JQ953995, JQ953976, JQ954224, JQ953826, JQ954063, JQ953715. Columnea guianensis C. V. Morton; J. F. Smith 3711 (SRP); Guyana and Venezulea; JQ953791, JQ953846, JQ954083, JQ953736, JQ954245, JQ953908, JQ954150, JQ953996, JQ953979, JQ954227, JQ953829, JQ954066, JQ953718. Columnea kucyniakii Raymond; T. Croat 94640 (MO); Ecuador; JQ953795, JQ953851, JQ954087, JQ953741, JQ954250, JQ953913, JQ954155, JQ954001, NA, NA, NA, NA, NA. Columnea paramicola (Wiehler) L. P. Kvist \& L. E. Skog; USBRG 1994-529; cultivated (Ecuador and Colombia); DQ211113, JQ953847, —, 一, JQ953737，JQ954246，JQ953909，JQ954151，JQ953997，JQ953977，JQ954225, JQ953827, JQ954064. Columnea purpusii Standl.; A. Rincon et al. 2302 (XAL); Mexico; JQ953792, JQ953848, JQ954084, JQ953738, JQ954247, JQ953910, JQ954152, JQ953998, _, JQ954228, JQ953830, JQ954067, JQ953719. Columnea scandens L*; J. L. Clark 8879 (US); South and Central America; JQ953793, JQ953849, JQ954085, JQ953739, JQ954248, JQ953911, JQ954153, JQ953999, NA, NA, NA, NA, NA. Columnea strigosa Benth.; J. F. Smith 1849 (WIS); Venezuela to Peru (Ecuador); JQ953794, JQ953850, JQ954086, JQ953740, JQ954249, JQ953912, JQ954154, JQ954000, JQ953981, JQ954230, JQ953832, JQ954069, JQ953721. Columnea tenella L. P. Kvist \& L. E. Skog; T. Croat 95108 (MO); Colombia and Ecuador; JQ953796, JQ953852, JQ954088, JQ953742, JQ954251, JQ953914, JQ954156, JQ954002, JQ953978, JQ954226, JQ953828, JQ954065, JQ953717.

Corytoplectus capitatus (Hook.) Wiehler; T. Croat 94581 (MO); Ecuador; JQ953798, JQ953860, JQ954095, JQ953749, JQ954258, JQ953922, JQ954165, JQ954010, JQ953958, JQ954206, JQ953809, JQ954046, JQ953698. Corytoplectus speciosus (Poepp.) Wiehler var. speciosus; USBRG 1994-268; cultivated (Ecuador); JQ953799, JQ953861, JQ954096, JQ953750, JQ954259, JQ953923, JQ954166, JQ954011, JQ953959, JQ954207, JQ953810, JQ954047, JQ953699.

Crantzia cristata (L.) Scop.; J. L. Clark 6546 (US); Martinique; DQ211154, JQ953862, 一, JQ953751, JQ954260, JQ953924, JQ954167, JQ954012, JQ953961, JQ954209, —, -, —. Crantzia epirotes (Leewenb.) J. L. Clark; D. Clarke 10172 (US); Guyana; DQ211153, JQ953863, JQ954097, JQ953752，JQ954261，JQ953925，JQ954168，JQ954013, JQ953962, JQ954210, JQ953812, JQ954049, JQ953702. Crantzia tigrina (H. Karst.) J. L. Clark; J. L. Clark 6892 (US); Venezuela; DQ211155, JQ953864, JQ954098, JQ953753, JQ954262, JQ953926, JQ954169, JQ954014, JQ953963, JQ954211, JQ953813, JQ954050, JQ953703.

Cremersia platula Feuillet \& L. E. Skog; J. J. de Granville 14868 (CAY); French Guiana; DQ211152, AY623152, AY623212, AY623257, AY623292, AY623222, JQ954170, AY623363, NA, NA, NA, NA, NA.

Drymonia coccinea (Aubl.) Wiehler; J. L. Clark 6492 (US); Ecuador; DQ211132, JQ953865, JQ954099, JQ953754, JQ954263, JQ953927, JQ954171, JQ954015, JQ953964, JQ954212, JQ953814, JQ954051, JQ953704. Drymonia longifolia Poepp.; J. L. Clark 6262 (US); Ecuador; AF543264, JQ953867, JQ954100, JQ953756, JQ954265, JQ953929, JQ954173, JQ954017, NA, NA, NA, NA, NA. Drymonia serrulata (Jacquin) Mart.; J. L. Clark 8843 (US); cultivated (Central and South America); DQ211133, JQ953866, —, JQ953755, JQ954264, JQ953928, JQ954172, JQ954016，JQ953965，JQ954213, JQ953815, JQ954052, JQ953705. Drymonia strigosa (Oerst.) Wiehler; J. L. Clark 8854 (US); cultivated (Mexico); DQ211143, JQ953868, JQ954101, JQ953757, JQ954266, JQ953930, JQ954174, JQ954018, JQ953966, JQ954214, JQ953816, JQ954053, JQ953706. Drymonia urceolata Wiehler; J. L. Clark 5225 (US); Ecuador; AF543265, JQ953869, JQ954102, JQ953758, JQ954267, JQ953931, JQ954175, JQ954019, JQ953967, JQ954215, JQ953817, JQ954054, JQ953707.

Episcia fimbriata Fritsch; J. F. Smith 3947 (SRP); cultivated (Brazil); JQ953800, JQ953870, JQ954103, JQ953759, JQ954268, JQ953932, JQ954176, JQ954020, NA, NA, NA, NA, NA. Episcia lilacina Hanst.; L. E. Skog 8132 (US); Costa Rica; -, AY363930, JQ954104, JQ953760, JQ954269, JQ953933, JQ954177, JQ954021, NA, NA, NA, NA, NA. Episcia lilacina Hanst.; J. L. Clark 8881 (US); Costa Rica; AY047091, - , - , - - , -, NA, NA, NA, NA, NA. Episcia sphalera Leewenb.; J. F. Smith 4136 (SRP); French Guiana; JQ953801, JQ953871, JQ954105, JQ953761, JQ954270, JQ953934, JQ954178, JQ954022, NA, NA, NA, NA, NA. Episcia xantha Leewenb. 1; J. F. Smith et al. 4116 (SRP); French Guiana and 
Guyana; JQ953802, JQ953872, JQ954106, —, JQ954271, JQ953935, JQ954179, JQ954023, NA, NA, NA, NA, NA. Episcia xantha Leewenb. 2; J. L. Clark 11323 (US); cultivated; JQ953803, JQ953873, —, —, JQ954272, —, JQ954180, JQ954024, NA, NA, NA, NA, NA.

Glossoloma anomalum J. L. Clark; J. L. Clark 6020 (US); Ecuador; AF543225, JQ953855, JQ954090, JQ953744, JQ954253, JQ953917, JQ954160, JQ954005, JQ953968, JQ954216, JQ953818, JQ954055, —. Glossoloma baguense (L. E. Skog) J. L. Clark; J. L. Clark 5448 (US); Ecuador; AF543226, JQ953853, JQ954089, JQ953743, —, JQ953915, JQ954157, JQ954003, NA, NA, NA, NA, NA. Glossoloma grandicalyx (J. L. Clark \& L. E. Skog) J. L. Clark; J. L. Clark 5449 (US); Ecuador; AF543218, JQ953854, —, 一, JQ954252, JQ953916, JQ954159, JQ954004, JQ953969, JQ954217, JQ953819, JQ954056, JQ953708. Glossoloma herthae (Mansf.) J. L. Clark; J. L. Clark 4598 (US); Ecuador; AF543230, JQ953856, JQ954091, JQ953745, JQ954254, JQ953918, JQ954161, JQ954006, NA, NA, NA, NA, NA. Glossoloma martinianum (J. F. Smith) J. L. Clark; J. L. Clark 5793 (US); Ecuador; AF543228, JQ953857, JQ954092, JQ953746, JQ954255, JQ953919, JQ954162, JQ954007, JQ953970, JQ954218, JQ953820, JQ954057, JQ953709. Glossoloma oblongicalyx J. L. Clark \& L. E. Skog; T. Croat 94373 (MO); Ecuador; JQ953797, JQ953858, JQ954093, JQ953747, JQ954256, JQ953920, JQ954163, JQ954008, NA, NA, NA, NA, NA. Glossoloma panamense (C. V. Morton) J. L. Clark; J. L. Clark 8612 (US); Panama; DQ211102, - , - - - - - - - - , - -, - - - -. Glossoloma panamense (C. V. Morton) J. L. Clark; L. E. Skog 7641 (US); cultivated (Panama); -, AY363933, AY623215, AY623260, AY623283, AY623305, JQ954158, AY623366, JQ953971, JQ954219, JQ953821, JQ954058, JQ953710. Glossoloma sprucei (Kuntze) J. L. Clark; J. L. Clark 6093 (US); Ecuador; AF543221, JQ953859, JQ954094, JQ953748, JQ954257, JQ953921, JQ954164, JQ954009, NA, NA, NA, NA, NA.

Lembocarpus amoenus Leewenb.; J. F. Smith 4125 (SRP); French Guiana; AY623399, AY623153, AY623213, AY623258, AY623293, AY623323, JQ954181, AY623364, NA, NA, NA, NA, NA.

Nautilocalyx adenosiphon (Leewenb.) Wiehler; L. E. Skog 7897 (US); cultivated (French Guiana and Venezuela); AF206227, AY363934, JQ954107, JQ953762, JQ954273, JQ953936, JQ954182, JQ954025, NA, NA, NA, NA, NA. Nautilocalyx melittifolius (L.) Wiehler; J. L. Clark 6540 (US); Martinique; AY047086, JQ953874, JQ954108, JQ953763, JQ954274, JQ953937, JQ954183, JQ954026, NA, NA, NA, NA, NA. Nautilocalyx pemphidius L. E. Skog; D. Bell 324 (US); Venezuela; DQ211176, JQ953875, JQ954109, JQ953764, JQ954275, JQ953938, JQ954184, JQ954027, NA, NA, NA, NA, NA. Nautilocalyx pictus (W. Hook.) Sprague; D. Clarke 9974 (US); Guyana; DQ211188, - , - - , 一, 一, 一, 一, NA, NA, NA, NA, NA. Nautilocalyx pictus (W. Hook.) Sprague; J. F. Smith 4118 (SRP); French Guiana; -, JQ953876, JQ954110, JQ953765, JQ954276, JQ953939, JQ954185, JQ954028, NA, NA, NA, NA, NA.

Nematanthus albus Chautems; J. L. Clark 6266 (US); cultivated (Brazil); AF543270, 一, 一, 一, 一, 一, 一, 一, NA, NA, NA, NA, NA. Nematanthus albus Chautems; J. F. Smith 3726 (SRP); cultivated (Brazil); -, AY623153, AY623216, AY623261, AY623281, AY623303, JQ954186, AY623367, NA, NA, NA, NA, NA. Nematanthus fissus (Vell.) L. E. Skog; J. F. Smith 3724 (SRP); cultivated (Brazil); JQ953804, JQ953877, JQ954111, JQ953766, JQ954277, JQ953940, JQ954187, JQ954029, NA, NA, NA, NA, NA. Nematanthus fritschii Hoehne; J. F. Smith 3720 (SRP); cultivated (Brazil); AY623400, AY623154, AY623217, AY623262, AY623294, AY623324, JQ954188, AY623368, NA, NA, NA, NA, NA. Nematanthus savannarum (C. V. Morton) J. L. Clark; K. Redden 1339 (US); Guyana; DQ211158, JQ953878, JQ954112, JQ953767, JQ954278, JQ953941, JQ954189, JQ954030, NA, NA, NA, NA, NA.

Neomortonia nummularia (Hanst.) Wiehler; J. L. Clark 6248 (US); Ecuador; AF543266, JQ953879, JQ954113, JQ953768, JQ954279, JQ953942, JQ954190, JQ954031, JQ953972, JQ954220, JQ953822, JQ954059, JQ953711. Neomortonia rosea Wiehler; J. L. Clark 7582 (US); Ecuador; DQ211099, JQ953880, —, JQ953769, JQ954280, JQ953943, JQ954191, JQ954032, JQ953973, JQ954221, JQ953823, JQ954060, JQ953712.

Oerstedina cerricola Wiehler; J. L. Clark 8700 (US); Panama; DQ211150, JQ953881, JQ954114, JQ953770, JQ954281, JQ953944, JQ954192, JQ954033, NA, NA, NA, NA, NA.

Paradrymonia aurea Wiehler; L. E. Skog 7979 (US); cultivated (Ecuador); AF206232, AY363932, JQ954115, JQ953771, JQ954282, JQ953945, JQ954193, JQ954034, NA, NA, NA, NA, NA. Paradrymonia aurea Wiehler; J. L. Clark 5409 (US); Ecuador; AF543274, JQ953886, JQ954120, JQ953776, JQ954287, JQ953950, JQ954198, JQ954039, NA, NA, NA, NA, NA. Paradrymonia campostyla (Leewenb.) Wiehler; J. L. Clark 8855 (US); cultivated (French Guiana); DQ211180, 一, 一, 一, -, 一, -, -, NA, NA, NA, NA, NA. Paradrymonia campostyla (Leewenb.) Wiehler; J. F. Smith 4137 (SRP); French Guiana; —, JQ953882, JQ954116, JQ953772, JQ954283, JQ953946, JQ954194, JQ954035, NA, NA, NA, NA, NA. Paradrymonia ciliosa (Mart.) Wiehler; D. Clarke 10239 (US); Guyana; DQ211182, -, - , , 一, - , , 一, NA, NA, NA, NA, NA. Paradrymonia ciliosa (Mart.) Wiehler; J. F. Smith 4114 (SRP); French Guiana; -, JQ953883, JQ954117, JQ953773, JQ954284, JQ953947, JQ954195, JQ954036, NA, NA, NA, NA, NA. Paradrymonia ciliosa (Mart.) Wiehler; R. Stewart s.n. (SRP); cultivated (Central America); JQ953805, JQ953884, JQ954118, JQ953774, JQ954285, JQ953948, JQ954196, JQ954037, NA, NA, NA, NA, NA. Paradrymonia densa (C. H. Wright) Wiehler; K. Redden 1060 (US); Guyana; DQ211184, 一, 一, 一, 一, —, 一, - NA, NA, NA, NA, NA. Paradrymonia densa (C. H. Wright) Wiehler; J. F. Smith 4115 (SRP); French Guiana; -, JQ953885, JQ954119, JQ953775, JQ954286, JQ953949, JQ954197, JQ954038, NA, NA, NA, NA, NA. Paradrymonia maculata (Hook. f.) Wiehler; J. F. Smith 4134 (SRP); French Guiana; JQ953806, JQ953887, JQ954121, JQ953777, JQ954288, JQ953951, JQ954199, JQ954040, NA, NA, NA, NA, NA. Paradrymonia metamorphophylla (Donn. Sm.) Wiehler; J. L. Clark 6028 (US); Ecuador; DQ211178, JQ953888, JQ954122, JQ953778, JQ954289, JQ953952, JQ954200, JQ954041, NA, NA, NA, NA, NA. Paradrymonia pedunculata L. E. Skog; USBRG 1994-184; unknown (Costa Rica and Panama); DQ211179, JQ953889, JQ954123, JQ953779, JQ954290, JQ953953, JQ954201, JQ954042, NA, NA, NA, NA, NA. 
Rhoogeton cyclophyllus Leewenb.; D. Clarke 10350 (US); Guyana; DQ211163, JQ953893, JQ954127, JQ953783, JQ954294, JQ953957, JQ954205, JQ954045, NA, NA, NA, NA, NA. Rhoogeton viviparus Leewenb.; D. Clarke 9255 (US); Guyana; DQ211164, JQ953892, JQ954126, JQ953782, JQ954293, JQ953956, JQ954204, JQ953892, NA, NA, NA, NA, NA.

Rufodorsia major Wiehler; J. F. Smith 3948 (SRP); cultivated (Costa Rica and Panama); JQ953807, JQ953890, JQ954124, JQ953780, JQ954291, JQ953954, JQ954202, JQ954043, NA, NA, NA, NA, NA. Rufodorsia minor Wiehler; J. F. Smith 3934 (SRP); cultivated (Costa Rica and Panama); JQ953808, JQ953891, JQ954125, JQ953781, JQ954292, JQ953955, JQ954203, JQ954044, NA, NA, NA, NA, NA.

\section{Outgroups}

Achimenes cettoana H. E. Moore; USBRG 1994-235; cultivated (Mexico); AY623371, AY623134, AY623176, AY623220, AY623265, AY623295, JQ954136, AY623325, NA, NA, NA, NA, NA.

Amalophyllon albiflorum (Rusby) Boggan, L. E. Skog \& E. H. Roalson; USBRG 1994-503; cultivated (Colombia); AY3732322, AY363914, AY623197, AY623242, AY364266, AY364288, JQ954134, AY623348, NA, NA, NA, NA, NA.

Gesneria pedicellaris Alain; J. F. Smith 3950 (SRP); cultivated (Dominican Republic); AY623393, AY623151, AY623206, AY623251, AY623287, AY623317, JQ954133, AY623357, NA, NA, NA, NA, NA.

Rhytidophyllum auriculatum Hook.; USBRG 1994-524; cultivated (Hispaniola and Puerto Rico); AF272232/AF272233, AY363927, AY623208, AY623252, AY364279, AY364301, JQ954135, AY623358, NA, NA, NA, NA, NA.

Sinningia cooperi (Paxt.) Wiehler; USBRG 1994-340; cultivated (Brazil); JQ953784, JQ953833, JQ954071, —, JQ954231, JQ953894, JQ954131, JQ953982, NA, NA, NA, NA, NA. Sinningia incarnata (Aubl.) D. L. Denham; J. L. Clark 8849; cultivated (Central and South America); JQ953785, JQ953834, JQ954072, JQ953723, JQ954232, JQ953895, JQ954132, JQ953983, NA, NA, NA, NA, NA. Sinningia richii Clayb.; USBRG 1994-554; cultivated (Brazil); AY372338/AY372355, AY623935, AY623219, AY623264, AY623285, AY364307, JQ954129, AY623370, NA, NA, NA, NA, NA. Sinningia speciosa (Lodd.) Hiern; J. F. Smith 4512 (SRP); cultivated (Brazil); AY372337/AY372354, AY363942, AY623218, AY623263, AY364284, AY363306, JQ954130, AY623369, NA, NA, NA, NA, NA.

Sphaerorrhiza sarmentiana (Gardner ex Hook.) Roalson \& Boggan; L. E. Skog 8220 (US); cultivated (Brazil); AY047079, GQ497208, JQ954070, JQ953722, GQ497193, AY047138, JQ954128, GQ497173, NA, NA, NA, NA, NA.

\section{Literature Cited}

$\rightarrow$ APG (Angiosperm Phylogeny Group) III 2009 An update of the Angiosperm Phylogeny Group classification for the orders and families of flowering plants: APG III. Bot J Linn Soc 161:105121.

$\rightarrow$ Barker FK, FM Lutzoni 2002 The utility of the incongruence length difference test. Syst Biol 51:625-637.

Boggan JK, LE Skog, EH Roalson 2008 A review of the Neotropical genera Amalophyllon, Niphaea and Phinaea (Gesneriaceae-Gloxinieae). Selbyana 29:157-176.

$\rightarrow$ Burleigh JG, MS Bansal, O Eulenstein, S Hartmann, A Wehe, TJ Vision 2011 Genome-scale phylogenetics: inferring the plant tree of life from 18,899 gene trees. Syst Biol 60:117-125.

Burtt BL 1970 Studies in the Gesneriaceae of the Old World. XXXIII. Some species of Cyrtandra, chiefly Bornean. Notes R Bot Gard Edinb 30:23-42.

1976 Notes on rain-forest herbs. Gard Bull Straits Settlem 29: 73-80.

$\rightarrow$ Citerne HL, M Möller, QCB Cronk 2000 Diversity of cycloidea-like genes in Gesneriaceae in relation to floral symmetry. Ann Bot 86:167-176.

$\rightarrow$ Chase MW, DE Soltis, RG Olmstead, D Morgan, DH Les, BD Mishler, MR Duvall, et al 1993 Phylogenetics of seed plants: an analysis of nucleotide sequences from the plastid gene $r b c L$. Ann Mo Bot Gard 80:528-580.

Clark JL 2005 A monograph of Alloplectus (Gesneriaceae). Selbyana 25:182-209.

2009 The systematics of Glossoloma (Gesneriaceae). Syst Bot Monogr 88:1-128.

$\rightarrow$ Clark JL, PS Herendeen, LE Skog, EA Zimmer 2006 Phylogenetic relationships and generic boundaries in the tribe Episcieae (Gesneriaceae) inferred from nuclear, chloroplast, and morphological data. Taxon 55:313-336.
Clark JL, EH Roalson, RA Pritchard, CL Coleman, V-H Teoh, J Matos 2011 Independent origin of radial floral symmetry in the Gloxinieae (Gesnerioideae: Gesneriaceae) is supported by the rediscovery of Phinaea pulchella in Cuba. Syst Bot 36:757-767.

$\rightarrow$ Clark JL, EA Zimmer 2003 A preliminary phylogeny of Alloplectus (Gesneriaceae): implications for the evolution of flower resupination. Syst Bot 28:365-375.

$\rightarrow$ Demesure B, N Sodzi, RJ Petit 1995 A set of universal primers for amplification of polymorphic non-coding regions of mitochondrial and chloroplast DNA in plants. Mol Ecol 4:129-131.

Dolphin K, R Belshaw, CDL Orme, DLJ Quicke 2000 Noise and incongruence: interpreting results of the incongruence length difference test. Mol Phylogenet Evol 17:401-406.

$\rightarrow$ Dowton M, AD Austin 2002 Increased congruence does not necessarily indicate increased phylogenetic accuracy: the behavior of the incongruence length difference test in mixed-model analyses. Syst Biol 51:19-31.

Doyle JJ, JL Doyle 1987 A rapid DNA isolation procedure for small quantities of fresh leaf tissue. Phytochem Bull 19:11-15.

$\rightarrow$ Emshwiller E, JJ Doyle 1997 Chloroplast-expressed glutamine synthetase $(n c p G S)$ : potential utility for phylogenetic studies with an example from Oxalis (Oxalidaceae). Mol Phylogenet Evol 12:310-319.

$\rightarrow$ Endress PK 2011 Evolutionary diversification of the flowers in angiosperms. Am J Bot 98:370-396.

$\rightarrow$ Farris JS 1989 The retention index and the rescaled consistency index. Cladistics 5:417-419.

$\rightarrow$ Farris JS, M Källersjö, AG Kluge, C Bult 1994 Testing significance of incongruence. Cladistics 10:315-319.

$\rightarrow$ Felsenstein J 1985 Confidence limits on phylogenies: an approach using the bootstrap. Evolution 39:783-791.

Fernández-Alonso JL 2006 Novedades taxonómicas y nomenclatur- 
ales en Cremosperma y Resia (Gesneriaceae) de Colombia. Rev Acad Colomb Cienc Exact Fís Nat 30:171-180.

Feuillet C 2009 Folia taxonomica. 12. Paradrymonia (Gesneriaceae: Episcieae) from the Guiana Shield: P. maguirei, a new species from Amazonas, and distribution and floral morphology of $P$. maculata. J Bot Res Inst Tex 3:133-138.

$\rightarrow$ Feuillet C, LE Skog 2003 Novae Gesneriaceae Neotropicarum. XI. New genera and species from the Guianas. Brittonia 54:344-351.

Hamilton MB 1999 Four primer pairs for the amplification of chloroplast intergenic regions with intraspecific variation. Mol Ecol 8:521-523.

Hentrich H 2008 The reproductive biology of Euglossine-pollinated plants in the natural reserve Nouragues, French Guiana. PhD diss. University of Ulm.

Hooker JD 1890 Paradrymonia maculata. Bot Mag 116, pl 7131.

$\rightarrow$ Huelsenbeck JP, F Ronquist 2003 MRBAYES: Bayesian inference of phylogeny. Bioinformatics 17:754-755.

$\rightarrow$ Jousselin E, J-Y Rasplus, F Kjellberg 2003 Convergence and coevolution in a mutualism: evidence from a molecular phylogeny of Ficus. Evolution 57:1255-1269.

Kriebel R 2010 Gesneriaceae. Pages 841-930 in BE Hammel, MH Grayum, C Herrera, N Zamora, eds. Manual de plantas de Costa Rica. Vol 5. Dicotiledóneas. Monogr Syst Bot Mo Bot Gard Vol 119. Missouri Botanical Garden, St. Louis.

$\rightarrow$ Kluge AG, SJ Farris 1969 Quantitative phyletics and the evolution of anurans. Syst Zool 18:1-32.

$\rightarrow$ Leebens-Mack JL, A Raubeson, L Cui, JV Kuehl, MH Fourcade, TW Chumley, JL Boore, RK Jansen, CW de Pamphilis 2005 Identifying the basal angiosperm node in chloroplast genome phylogenies: sampling one's way out of the Felsenstein zone. Mol Biol Evol 22: 1948-1963.

Leeuwenberg AJM 1980 Notes on American Gesneriaceae: 7. Misc Pap Landbouwhogesch Wageningen 19:239-244.

$\rightarrow$ Malcomber ST 2002 Phylogeny of Gaertnera Lam. (Rubiaceae) based on multiple DNA markers: evidence of a rapid radiation in a widespread, morphologically diverse genus. Evolution 56:42-57.

$\rightarrow$ Mason-Gamer RJ, EA Kellogg 1996 Testing for phylogenetic conflict among molecular data sets in the tribe Triticeae (Gramineae). Syst Biol 45:524-545.

$\rightarrow$ Mayer V, M Möller, M Perret, A Weber 2003 Phylogenetic position and generic differentiation of Epithemateae (Gesneriaceae) inferred from plastid DNA sequence data. Am J Bot 90:321-329.

$\rightarrow$ Miller JS, A Kamath, RA Levin 2009 Do multiple tortoises equal a hare? the utility of nine noncoding plastid regions for species-level phylogenetics in tribe Lycieae (Solanaceae). Syst Bot 34:796-804.

$\rightarrow$ Möller M, QCB Cronk 1997 Phylogeny and disjunct distribution: evolution of Saintpaulia (Gesneriaceae). Proc R Soc B 264:1827-1836.

$\rightarrow$ Möller M, M Pfosser, C-G Jang, V Mayer, A Clark, ML Hollingsworth, MHJ Barfuss, Y-Z Wang, M Kiehn, A Weber 2009 A preliminary phylogeny of the "didymocarpoid Gesneriaceae" based on three molecular data sets: incongruence with available tribal classifications. Am J Bot 96:989-1010.

Morton CV 1948 Gesneriaceae. In B. Maguire Plant Explorations in Guiana in 1944, chiefly to the Tafelberg and the Kaieteur Plateau, special issue, Bull Torrey Bot Club 75:563-566.

$\rightarrow$ Müller K 2004 PRAP: computation of Bremer support for large data sets. Mol Phylogenet Evol 31:780-782.

Mummenhoff K, A Franzke, M Koch 1997 Molecular data reveal congruence in fruit characters used in the classification of Thlaspi s.l. (Brassicaceae). Bot J Linn Soc 125:183-199.

$\rightarrow$ Nylander JAA, JC Wilgenbusch, DL Warren, DL Swofford 2008 AWTY (are we there yet?): a system for graphical exploration of MCMC convergence in Bayesian phylogenetics. Bioinformatics 24:581-583.

Oxelman B, M Lidén, D Berglund 1997 Chloroplast rps16 intron phylogeny of the tribe Sileneae (Caryophyllaceae). Plant Syst Evol 12:250-272.

$\rightarrow$ Palmer JD, D Zamir 1982 Chloroplast DNA evolution and phylogenetic relationships in Lycopersicon. Proc Natl Acad Sci USA 79: 5006-5010.

$\rightarrow$ Perret M, A Chautems, R Spichiger, G Kite, V Savolainen 2003 Systematics and evolution of tribe Sinningieae (Gesneriaceae): evidence from phylogenetic analyses of six plastid DNA regions and nuclear $n c p G S$. Am J Bot 90:445-460.

$\rightarrow$ Posada D, TR Buckley 2004 Model selection and model averaging in phylogenetics: advantages of Akaike information criterion and Bayesian approaches over likelihood ratio tests. Syst Biol 53:793-808.

$\rightarrow$ Posada D, KA Crandall 1998 MODELTEST: testing the model of DNA substitution. Bioinformatics 14:817-818.

Rambaut A, AJ Drummond 2005 Tracer v1.4. http://beast.bio.ed .ac.uk/Tracer.

Roalson EH, JK Boggan, LE Skog 2005a Reorganization of tribal and generic boundaries in the Gloxinieae (Gesneriaceae: Gesnerioideae) and the description of a new tribe in the Gesnerioideae, Sphaerorrhizeae. Selbyana 25:225-238.

Roalson EH, JK Boggan, LE Skog, EA Zimmer 2005b Untangling Gloxinieae (Gesneriaceae). I. Phylogenetic patterns and generic boundaries inferred from nuclear, chloroplast, and morphological cladistic datasets. Taxon 54:389-410.

$\rightarrow$ Roalson EH, LE Skog, EA Zimmer 2008 Untangling Gloxinieae (Gesneriaceae). II. Reconstructing biogeographic patterns and estimating divergence times among New World continental and island lineages. Syst Bot 33:159-175.

$\rightarrow$ Seelanen T, A Schnabel, JF Wendel 1997 Congruence and consensus in the cotton tribe (Malvaceae). Syst Bot 22:259-290.

$\rightarrow$ Shaw J, EB Lickey, EE Schilling, RL Small 2007 Comparison of whole chloroplast genome sequences to choose noncoding regions for phylogenetic studies in angiosperms: the tortoise and the hare III. Am J Bot 94:275-288.

Skog LE 1978 Flora of Panama, family 175. Gesneriaceae. Ann Mo Bot Gard 65:783-996.

Skog LE, FF de Jesus 1997 A review of Resia (Gesneriaceae). BioLlania, Ed Espec 6:515-525.

Skog LE, C Feuillet 2008 Flora of the Guianas, series A: 26: Gesneriaceae. Royal Botanic Gardens, Kew.

$\rightarrow$ Simmons MP, H Ochoterena 2000 Gaps as characters in sequencebased phylogenetic analyses. Syst Biol 49:369-381.

$\rightarrow$ Smith JF 1994 Systematics of Columnea sections Pentadenia and Stygnanthe (Gesneriaceae). Syst Bot Monogr 44:1-89.

$\rightarrow \longrightarrow 1996$ Tribal relationships within the Gesneriaceae: a cladistic analysis of morphological data. Syst Bot 21:497-514.

$\rightarrow-2000 a$ A phylogenetic analysis of tribes Beslerieae and Napeantheae (Gesneriaceae) and evolution of fruit types: parsimony and maximum likelihood analyses of $n d h F$ sequences. Syst Bot 25:72-81.

$\rightarrow-2000 b$ Phylogenetic resolution within the tribe Episcieae (Gesneriaceae): congruence of ITS and $n d h F$ sequences from parsimony and maximum-likelihood analyses. Am J Bot 87:883-897.

$\rightarrow-2000 c$ Phylogenetic signal common to three datasets: combining data which initially appear heterogeneous. Plant Syst Evol 221:179-198.

Smith JF, S Atkinson 1998 Phylogenetic analysis of the tribes Gloxinieae and Gesnerieae (Gesneriaceae): data from ndbF sequences. Selbyana 19:122-131.

$\rightarrow$ Smith JF, CL Carroll 1997 A cladistic analysis of the tribe Episcieae (Gesneriaceae) based on $n d h F$ sequences: origin of morphological characters. Syst Bot 22:713-724.

$\rightarrow$ Smith JF, SB Draper, LC Hileman, DA Baum 2004a A phylogenetic analysis within tribes Gloxinieae and Gesnerieae (Gesnerioideae: Gesneriaceae). Syst Bot 29:947-958.

$\rightarrow$ Smith JF, LC Hileman, MP Powell, DA Baum $2004 b$ Evolution of 
GCYC, a Gesneriaceae homolog of CYCLOIDEA, within Gesnerioideae (Gesneriaceae). Mol Phylogenet Evol 31:765-779.

$\rightarrow$ Smith JF, M Kresge, M Møller, and QCB Cronk 1998 The African violets (Saintpaulia) are members of Streptocarpus subgenus Streptocarpella (Gesneriaceae): combined evidence from chloroplast and nuclear ribosomal genes. Edinb J Bot 55:1-11.

$\rightarrow$ Smith JF, KJ Sytsma 1994a Evolution in the Andean epiphytic genus Columnea (Gesneriaceae). I. Morphology. Syst Bot 19:220-235.

$\rightarrow-1994 b$ Evolution in the Andean epiphytic genus Columnea (Gesneriaceae). II. Chloroplast DNA restriction site variation. Syst Bot 19:317-336.

$\rightarrow-1994 c$ Molecules and morphology: congruence of data in Columnea (Gesneriaceae). Plant Syst Evol 193:37-52.

$\rightarrow$ Smith JF, JC Wolfram, KD Brown, CL Carroll, DS Denton 1997 Tribal relationships in the Gesneriaceae: evidence from DNA sequences of the chloroplast gene ndhF. Ann Mo Bot Gard 84:50-66.

Soltis DE, PS Soltis, DL Nickrent, LA Johnson, WJ Hahn, SB Hoot, JA Sweere, et al 1998 Angiosperm phylogeny inferred from 18S ribosomal DNA sequences. Ann Mo Bot Gard 4:1-49.

Swofford DL 2002 PAUP*: phylogenetic analysis using parsimony ("and other methods), version 4.0b10. Sinauer, Sunderland, MA.

$\rightarrow$ Taberlet P, L Gielly, G Pautou, J Bouvet 1991 Universal primers for amplification of three non-coding regions of chloroplast DNA. Plant Mol Biol 17:1105-1110.

$\rightarrow$ Tekle Y, LW Parfrey, LA Katz 2009 Molecular data are transforming hypotheses on the origin and diversification of eukaryotes. Bioscience 59:471-481.

Thiers B 2011 Index Herbariorum: a global directory of public herbaria and associated staff [continuously updated]. New York Botanical Garden's Virtual Herbarium, New York. http://sweetgum .nybg.org/ih/.

$\rightarrow$ Vences M, J Kosuch, R Boistel, CFB Haddad, E La Marca, S Lötters, M Veith 2003 Convergent evolution of aposematic coloration in Neotropical poison frogs: a molecular phylogenetic perspective. Org Divers Evol 3:215-226.

Wang Y-Z, R-H Liang, B-H Wang, J-M Li, Z-J Qiu, Z-Y
Li 2010 Origin and phylogenetic relationship of the Old World Gesneriaceae with actinomorphic flowers, inferred from nrDNA (ITS) and cpDNA (trnL-F) sequence data. Taxon 59:1044-1052.

Wang Y-Z, R-B Mao, Y Liu, J-M Li, Z-Y Li, Y Dong, JF Smith 2011 Phylogenetic reconstruction of Chirita and allies (Gesneriaceae) with taxonomic treatments. Taxon 49:50-64.

Weber A 2004 Gesneriaceae. Pages 63-158 in K Kubitzki, JW Kadereit, eds. The families and genera of vascular plants. Vol 7. Flowering plants, Dicotyledons: Lamiales (except Acanthaceae including Avicenniaceae). Springer, Berlin.

Wiehler H 1975a Neomortonia, a new genus in the Gesneriaceae. Selbyana 1:16-21.

- 1975b Rufodorsia, a new Central-American genus in the Gesneriaceae. Selbyana 1:138-149.

1978 Miscellaneous transfers and new species of Neotropical Gesneriaceae. Selbyana 5:61-93.

1983 Synopsis of the Neotropical Gesneriaceae. Selbyana 6: $1-219$.

2002 I.D. illustrated digest of Neotropical Gesneriaceae. XIII pp. +218 plates. Friends of the Gesneriad Research Foundation, Sarasota, FL.

$\rightarrow$ Woo VL, MM Funke, JF Smith, PJ Lockhart, PJ GarnockJones 2011 New World origins of southwest Pacific Gesneriaceae: multiple movements across and within the South Pacific. Int J Plant Sci 172:434-457.

$\rightarrow$ Yoder AD, JA Irwin, BA Payseur 2001 Failure of the ILD to determine data combinability for slow loris phylogeny. Syst Biol 50:408-424.

$\rightarrow$ Zimmer EA, EH Roalson, LE Skog, JK Boggan, A Idnurm 2002 Phylogenetic relationships in the Gesnerioideae (Gesneriaceae) based on nrDNA and cpDNA trnL-F and trnE-T spacer region sequences. Am J Bot 89:296-311.

Zwickl DJ 2006 Genetic algorithm approaches for the phylogenetic analysis of large biological sequence datasets under the maximum likelihood criterion. PhD diss. University of Texas, Austin. 